\title{
Place and Contingency Differential Responses of Monkey Septal Neurons during Conditional Place-Object Discrimination
}

\author{
Toshiaki Kita, ${ }^{2}$ Hisao Nishijo, ${ }^{1}$ Satoshi Eifuku, ${ }^{1}$ Katsutoshi Terasawa, ${ }^{2}$ and Taketoshi Ono ${ }^{1}$ \\ Departments of ${ }^{\prime}$ Physiology and ${ }^{2}$ Japanese Oriental Medicine, Faculty of Medicine, Toyama Medical and \\ Pharmaceutical University, Sugitani 2630, Toyama 930-01, Japan
}

To elucidate spatial and cognitive function of the septal nuclei, neural activity was recorded from alert monkeys during performance of a place-dependent go/no-go (PGN) task. Response/reinforcement contingencies of given objects were conditional upon the location of a motorized, movable device (cab) containing a monkey in one of four places. The task was initiated by presentation of the outside view (place phase) followed by presentation of an object (object phase) selected from a total of four. A lever press was reinforced only if the correct object was seen in its corresponding place, and the same object was never reinforced in any of the other three places.

of 430 septal neurons recorded, the responses during the place phase in the four places were significantly different in $\mathbf{5 8}$ neurons. Responses of eight of these neurons were also place-differential during the object phase as well as the place phase. Furthermore, when the outside view was not presented before the object phase, differential responses in the object phase disappeared. Responses of 91 neurons in the object phase were differential in terms of go/no-go responses and reward availability. Of these 91 neurons, 72 were further tested on a place-independent asymmetrical go/no-go (AGN) task, which required no conditional discrimination. Forty-three neurons responded differentially only in the PGN task. It is thus concluded that this PGN-specific activity reflected conditional place-object relations. Of the remaining 29 neurons that responded differentially in both tasks, 21 were further tested by a place-independent symmetrical go/no-go task (no-go responses were also rewarded). Responses of 19 of these 21 neurons were related to the reward/nonreward contingency but not to the response contingency. The results suggest that septal nuclei are involved in integrating spatial information, conditional place-object relations, and reward/ nonreward contingency.

[Key words: septal nuclei, monkey, neural activity, place, go/no-go task, conditional discrimination, reward, nonreward]

\footnotetext{
Received Apr. 19, 1994; revised Aug. 9, 1994; accepted Sept. 12, 1994

We thank Dr. B. McNaughton (University of Arizona), Dr. J. Bures (Academy of Sciences of C.zech Republic), and Dr. A. Simpson (Showa University) for help in preparing the manuscript, and Ms. M. Yamazaki and Ms. A. Tabuchi for typing. This work was supported partly by the Japanese Ministry of Education. Science and Culture Grants-in-Aid for Scientific Research $(05267103$ 06454706 and 06680786), and by Uehara Memorial Foundation, and by the Human Frontier Science Program for the 3rd fiscal year.

Correspondence should be addressed to Professor Taketoshi Ono, M.D., Ph.D., at the above address.

Copyright 1995 Society for Neuroscience $0270-6474 / 95 / 151683-21 \$ 05.00 / 0$
}

Extensive lesion studies have indicated that the septal region is critically involved in learning and memory (for review, see Gray and McNaughton, 1983). Anatomically the septal nuclei receive one of their main inputs from the hippocampus (Raisman, 1966; Siegel et al., 1975; Swanson et al., 1987). It has also been established that septal nuclei receive afferent fibers from association cortices, which are related to higher brain functions, such as around the principal sulcus in the monkey prefrontal cortex (Tanaka and Goldman, 1976), and the prelimbic cortex in rats (Beckstead, 1979). Interestingly, both of these two prefrontal areas in different species (for reviews, see Rosenkilde, 1983; Kolb, 1984), as well as the hippocampus (O'Kcefe and Nadel, 1978), have been known to participate in the processing of spatial mapping or spatial information.

Lesions in the medial frontal cortex, including the prelimbic cortex, as well as septohippocampal lesions impaired responses of rats in the Morris water maze (Sutherland et al., 1982), spatial delayed alternation (Brito et al., 1982; Brito and Brito, 1990; also see Eichenbaum et al., 1983), spatial delayed non-matchingto-sample (Thomas and Spafford, 1984; Shaw and Aggleton, 1993), and spatial problem solving (Poucet and Hcrrmann, 1990). Recently, the frontocortical-septal pathway was found to use glutamate as a neurotransmitter (Jaskiw et al., 1991) and, from its disconnection study, to be important in learning a radial arm maze (Ammassari-Teule et al., 1993). In monkeys, lesions of the principal sulcus and the septohippocampal system impair performance in a spatial delayed alternation task (Mishkin, 1957; Butters and Rosvold, 1968). Altogether, one can assume that the septal nuclei occupy a critical position in the integration of spatial information and reinforcement contingency, because they rcceive inputs from both the hippocampus and specific prefrontal areas, and have extensive reciprocal connections with the hypothalamus (Raisman, 1966).

It has also been suggested that the septohippocampal system may participate in various kinds of conditional discrimination learning in rats (Hirsh, 1980; Ross et al., 1984; Sutherland and Rudy, 1989; Good and Honey, 1991), in monkeys (Gaffan and Harrison, 1989a,b), and in humans (Petrides, 1985b). For example, rat hippocampal lesions produced deficits in a conditional go/no-go task in which stimulus $\mathrm{X}$ was reinforced when it was presented in context $A$ and nonreinforced in context $B$, and stimulus $Y$ was reinforced in context $B$ and nonreinforced in context A (Good and Honey, 1991). In monkeys, fornix transection impaired choice accuracy in a task in which they were required to choose one of two objects when a fixed scene could be viewed at the monkey's left, and the other object when the scene could be viewed at the right (Gaffan and Harrison, 1989b). Thus, an- 
imals with lesions in the septohippocampal system failed to use background itself or spatial relations of contents in the background to decide whether or not a given object choice was rewarded in spatial-visual conditional discrimination tasks. Impairment in a similar spatial-visual conditional learning task was reported to be produced by brain lesions in the principal sulcus, as well as the fornix (Gaffan and Harrison, 1989a).

The present study was undertaken to examine functional roles of septal nuclei in learning and remembering spatial-visual conditional discrimination. Activity of monkey septal neurons was recorded during performance of a place-dependent go/no-go (PGN) task that had both spatial and conditional relations. In this task, the response/reinforcement contingency of each object differed as the monkey's location changed, so it was necessary to distinguish four different places where the animal could be in the experimental room and evaluate each of four objects for both its own characteristics and its relation to the animal's location. Neural activity in response to the presentation of outside views and discriminable objects was analyzed with respect to difference in the animal's location and response/reinforcement contingency. More precise correlation of contingency-differential activity was estimated by using two other unconditional place-independent go/no-go tasks (asymmetrically and symmetrically reinforced). Accordingly, it was possible to determine whether the contingency-differential activity reflected either conditional place-object association, reward/nonreward contingency, or response contingency.

\section{Materials and Methods}

Animals and experimental design. Two male Macaca fuscata weighing 3.8 and $6.0 \mathrm{~kg}$ were used. A monkey was restrained painlessly in a stereotaxic apparatus by a surgically fixed head holder and sat in a chair in a cab which was set in a $2.5 \times 2.5 \mathrm{~m}$ field located within a $5 \times 6$ m experimental room (Fig. $1 \Lambda$ ), as previously described (Ono et al., 1991, 1993). During a recording session eye movement was monitored by electrooculogram (EOG). The room, illuminated at 140 lux, contained several visual landmarks, such as a refrigerator, a table, a rack, and some experimental devices. It is emphasized that the monkey faced toward the right side of Figure $1 B$ throughout the training and recording sessions. The cab was moved in lateral, anterior-posterior, and diagonal directions from one place to another by computer controlled electric motors. The front, left and right walls of the cab were made of halfmirrored Plexiglas and the rear wall was a steel plate equipped with two lamps (cab lamps) and two speakers on the inside. The landmarks in the room could be seen from inside of the cab through the halfmirrored walls only when the cab lamps were extinguished (time constant of a decreasing rate of illuminance, $30 \mathrm{msec}$ ). Intensity of illumination inside the cab was 70 lux when the cab lamps were on, and 10 lux when the cab lamps were off. The included angle of the visible range outside of the cab was $68^{\circ}$. Photographs taken through a video camera in the cab at each of the four recording locations are shown in Figure 2 (because of the limits of the video camera, only $33^{\circ}$ included angle of the visual field can be shown). The upper part of the front wall also contained a double half-mirrored $15 \times 15 \mathrm{~cm}$ shutter just above an operant responding lever. There was an illuminated stage for object presentation behind the shutter and an object on the stage was visible to the monkey through the shutter when a front lamp was on (time constant of the rise of illuminance, $50 \mathrm{msec}$ ). Juice, controlled by an electromagnetic valve, was delivered from a tube that projected through the rear wall.

Place-dependent go/no-go ( $P G N$ ) task. The cab was always placed in one of the four corners of the field, but the corner was changed at random from trial to trial. One three-dimensional object, selected from a total of four, was presented at one time or another, in each place. Each of the objects, which were rectangular parallelcpipeds made of differently colored blocks (object 1 made of red and white blocks; object 2 , blue and white; object 3, green and white; object 4 , yellow and white), predicted a reward only when presented in one corresponding place (go trial), and the same object predicted nonreward in all other places (no-
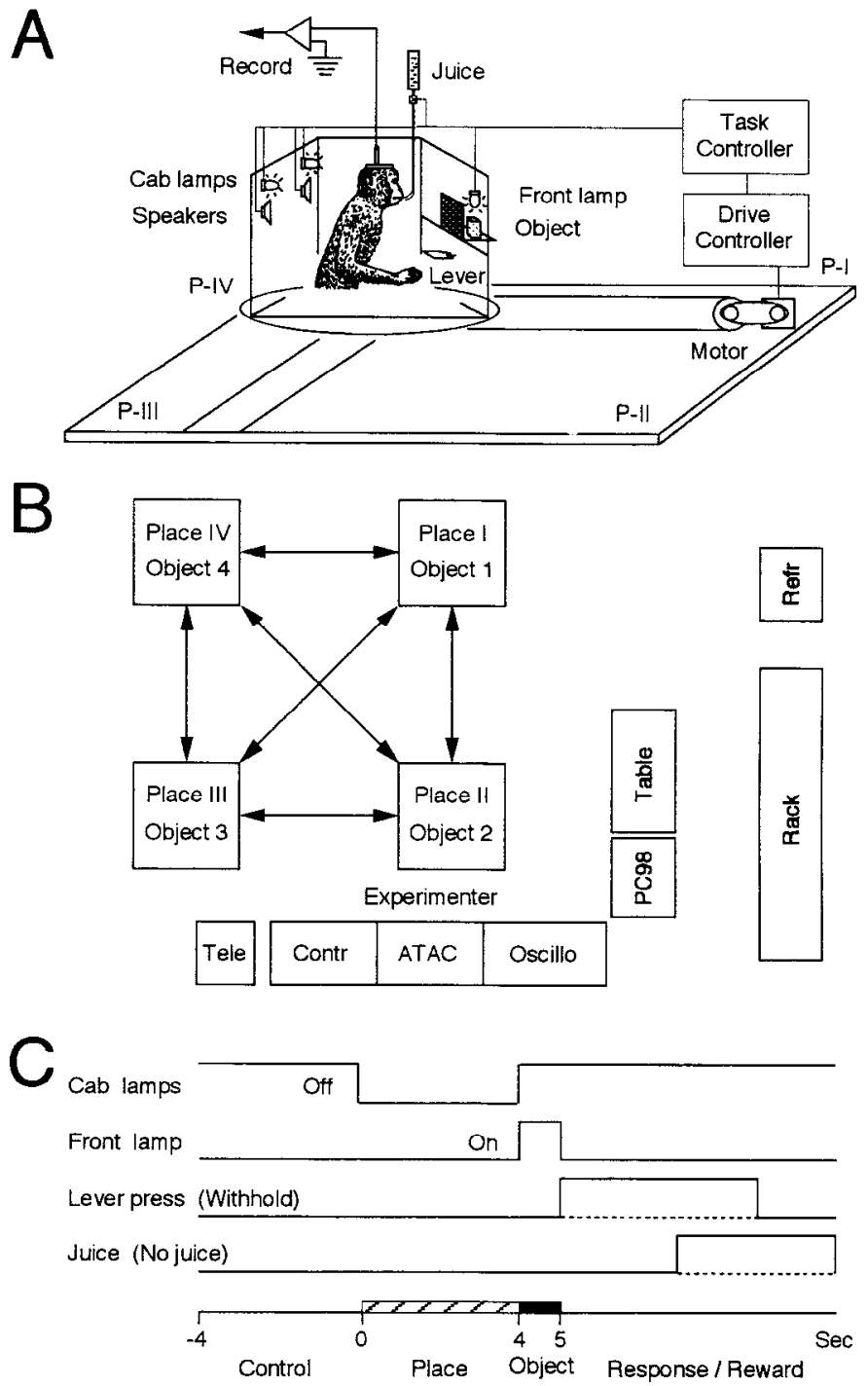

Figure 1. Schema of the experimental set-up and paradigm. A, Movable monkey cab. The monkey sat in a chair placed in a $0.7 \mathrm{~m}$ long $\times$ $0.8 \mathrm{~m}$ wide $\times 0.85 \mathrm{~m}$ high cab. Front, left and right walls of the cab were half-mirrored. The rear wall, made of steel, was equipped with two cab lamps and speakers. A half-mirrored shutter $(15 \times 15 \mathrm{~cm})$ was in the upper half of the cab front wall just above an operant lever. A front lamp behind the shutter illuminated an object in the bay. $B$, Entire apparatus in experimental shielded room $(5 \times 6 \mathrm{~m})$. The cab was moved to one of four places (Places $I-I V$ ) in $2.5 \times 2.5 \mathrm{~m}$ space. Each of four objects (Objects 1-4) indicated a reward only when it was presented in its own corresponding place, as in the figure. Tele, telemeter; Contr, controller; ATAC, microcomputer ATAC 3700; Oscillo, oscilloscope; PC98, microcomputer; Refr, refrigerator. $C$, Time sequences of placedependent go/no-go (PGN) task. During $4 \mathrm{sec}$ cab-lamp-off, monkey could see room environment through half-mirrored walls (place phase). While the front lamp was on for $1 \mathrm{sec}$, a given object was visible behind the shutter (object phase). If the object meant a reward, a drop of juice was dispensed from spout after keeping the lever pressed for $3 \mathrm{sec}$ (go trial). If the object meant a nonreward, juice was never available and pressing the lever produced a loud coarse buzzer sound (no-go trial).

go trials). For example, object 1 meant a reward in place I, and nonreward in places II, III, or IV (Fig. 1B). Consequently, each object presented two variable response/reinforeement contingencies depending on the location in which the monkey encountered it; there was a go/ reward contingency and a no-go/nonreward contingency.

Each trial consisted of four phases (Fig. $1 C$ ). The control phase was a period of $4 \mathrm{sec}$ before each trial. A trial was initiated by turning off 


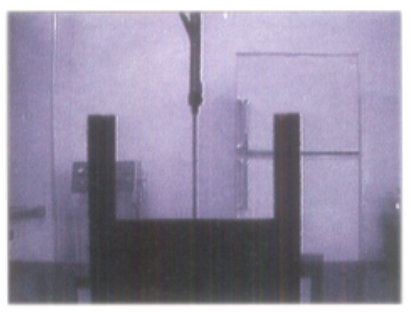

Place-I

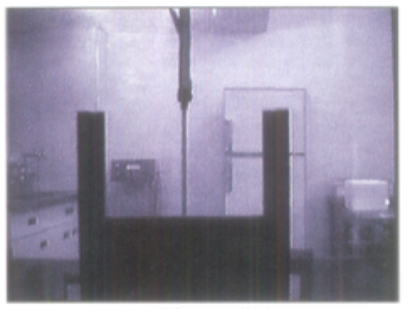

Place-IV

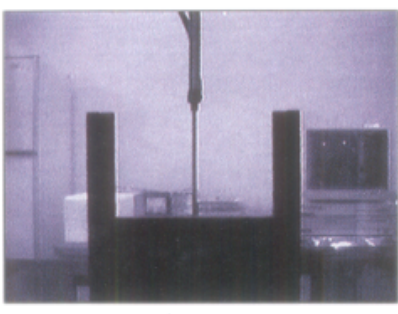

Place-II

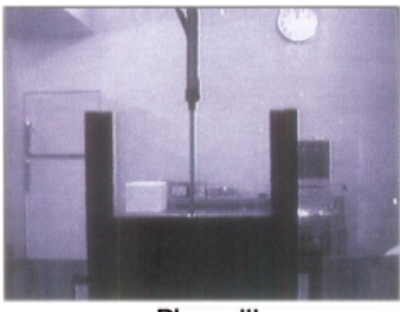

Place-III
Figure 2. Photographs indicating outside views during the place phase at each animal's location (Places $I-I V$ ). Photographs taken from a video camera located in the cab through the half-mirrored front wall. The black $U$ shape includes a double half-mirrored shutter, which is opaque except during the object phase, and the shutter tracks which are always opaque. The left and right edges of each photograph correspond to an included angle of $33^{\circ}$ of the visual field of the monkey in each respective place.

the inside cab lamps with a click sound. While the cab lamps were off for $4 \mathrm{sec}$ (place phase), the monkey could see outside of the cab through the half-mirrored cab walls. In the following object phase, a front lamp was lit for $1 \mathrm{sec}$ to illuminate an object behind the half-mirrored shutter. If a given object meant a reward in that place (go trial), the monkey was required to initiate a response within $7 \mathrm{sec}$ after the end of the object phase and hold the lever down for $3 \mathrm{sec}$. After the lever was pressed for $3 \mathrm{sec}$, a reward of $0.3 \mathrm{ml}$ of orange juice was presented for $4 \mathrm{sec}$ (response/reward phase in a correct go trial). If a given object meant a nonreward in that place (no-go trial) and the monkey pressed the lever during the $7 \mathrm{sec}$ period after the object phase, a buzzer tone was presented for $1 \mathrm{sec}$ to indicate a nonreward (an error no-go trial). If the lever had not been pressed for the $7 \mathrm{sec}$ period in a go or no-go trial, the trial finished without any event (as an error if a go trial, or correct if a no-go trial). The cab was moved to the next place during an intertrial interval (ITI) of 30-40 sec after the end of each trial and arrived at the new position before the control phase of the next trial. The object was also exchanged by the experimenter during the ITI. Place-object combinations were chosen in a pseudorandom, balanced fashion so that go and no-go trials each comprised half of the total trials, with the further condition that the same response (go or no-go) did not occur more than four times in succession. In training, the same no-go trial was repeated when the monkey pressed the lever in a no-go trial so that the monkey could learn to withhold an improper go response. The ITI was prolonged to $1 \mathrm{~min}$ after an error, either in a nogo trial (error of commission) or a go-trial (error of omission).

In some recording sessions, to analyze effects of the environment outside of the cab, a reversed object place version of the PGN task $(R O P)$ was introduced after completing the PGN task, since responses of some neurons to an object depended on the monkey's location described in detail in Results. In this test, the start of each trial was indicated by the click sound only. After $4 \mathrm{sec}$, the front lamp was turned on for $1 \mathrm{sec}$ for the object phase. After the object phase the inside cab lights were turned off so the monkey could see the environment outside of the cab. The remaining procedures were the same as those of the PGN task, and a lever press was reinforced by a juice reward only if the correct object was seen in its corresponding place. Usually, before it could see outside of the cab, the monkey pressed the lever at the chance level during the object phase described in detail in Results.

Place-independent asymmetrical go/no-go (AGN) task. In this task, the cab was placed in any one of the four locations utilized in the PGN task, and two objects other than those used in the PGN task were pre- sented at random. Regardless of the animal's location, a white object meant a reward, and a yellow object indicated no reward. Except for this point, the other task sequences, such as presentation of the outside views (place phase), presentation of the objects (object phase), lever pressing in a go trial, and delivery of juice reward only in a go trial (response/reward phase), were the same as those of the PGN task. Consequently, the white object was always connected with a go/reward contingency and the yellow object, with a no-go/nonreward contingency. Therefore, this task was regarded as an unconditional place-independent version of the PGN task.

Place-independent symmetrical go/no-go (SGN) task. This task was similar to the AGN task except that correct response in a no-go trial was associated with juice reward as well as in a go trial. The white object which was used in the AGN task was also presented in a go tria and a black object used only in this task was presented in a no-go trial. The white and black objects differed in response contingency, but were the same in reward contingency. That is, the black object was constantly associated with a no-go/reward contingency.

Combination of tasks. When a neuron was located, it was tested with the PGN task first. It was tested in this task at least until the neural responses to the four objects in each place were perfectly recorded. In each of four places, at least three go trials with the same object and three no-go trials using each of three other objects were tested so that go and no-go trials each comprised half of the total trials. Therefore, it took at least 24 trials (6 trials at each of four places) with no error to test all 16 patterns of place-object combinations (e.g., see Fig. 4A). Usually more than 32 trials were carried out to permit estimation of the responsiveness of the neuron. The AGN and SGN tasks were then introduced in one of the four places. Each object used in the AGN and SGN tasks was presented in five or more trials. After a session of either the AGN or SGN task, the PGN task was again introduced to confirm the responsiveness of the recorded neuron. Usually, 150-200 trials were run in pseudorandom order each day during a recording session.

Training and surgery. The monkeys were first trained in the PGN task. In the first step, they were trained with two objects (objects 1 and 2 ) in one location (place I), and then with same two objects in another location (place II). In this step, this task could be regarded as reversal learning. In the next step, they were trained at one of two locations (places I and II) at random until they became able to solve this task as a conditional discrimination task. In the final step, other objects (objects 3 and 4) and other locations (places III and IV) were gradually added. After they learned to perform the final step of the PGN task to a criterion of more than $90 \%$ correct ( $2-3 \mathrm{hr} \times 5 \mathrm{~d}$ per week, $12-14$ weeks), a head-restraining device was attached to the skull under asepsis and sodium pentobarbital anesthesia $(35 \mathrm{mg} / \mathrm{kg}$, i.m.). Heart and respiratory functions, and rectal temperature were monitored on a polygraph system (Nihon Kohden). Rectal temperature during anesthesia was maintained at $37 \pm 0.5^{\circ} \mathrm{C}$ by a blanket heater. A U-shaped aluminum plate for a head-restraining device was anchored with dental acrylic to stainless steel bolts inserted in keyhole slots in the skull. Antibiotics were administered topically and systemically for a week to protect against infection. Two weeks after surgery, the animals were retrained. Performance criteria for the PGN task were again attained in 1-2 weeks, and they then readily learned the other tasks to criterion in 2-3 weeks. All monkeys were treated in strict compliance with National Institutes of Health policy on the humane care and use of laboratory animals.

Recording and data analysis. A glass-insulated tungsten microelectrode $(1-2 \mathrm{M} \Omega$ at $1000 \mathrm{~Hz})$ was stereotaxically inserted into the septal nuclei stepwise by a pulse motor-driven manipulator (SM-21, Narishige) at an angle of $20^{\circ}$ from vertical to avoid injury around the superior sagittal sinus. Extracellular neural activity was passed through a high input impedance preamplifier made of a dual-channel field-effect transistor (2SK389, Toshiba Electric), amplified by a main amplifier, transmitted by a telemeter system (Nihon Kohden), monitored on an oscilloscope, and recorded on magnetic tape (A-614, Sony Magnescale). Neural activity was processed through a window discriminator and counted by a rate meter. The spikes and lever presses were recorded over an interval of $20.48 \mathrm{sec}$ by an on-line minicomputer (ATAC 3700, Nihon Kohden), and displayed as peristimulus time histograms with 100 bins of $200 \mathrm{msec}$ each by another computer (PC-9801, NEC).

Excitatory or inhibitory responses were defined by analysis of variance (ANOVA) between spontaneous activity in the pretrial control phase and activity in the $4 \mathrm{sec}$ of the place phase or $1 \mathrm{sec}$ of the object phase (from 0.2 to $1.2 \mathrm{sec}$ after onset of the front lamp on) $(p<0.05$ ). In the PGN task, responses in the place phase, recorded for $4 \mathrm{sec}$ in the 
Table 1. Number, spontaneous firing rate, and latency of each type of visually responsive septal neurons

\begin{tabular}{|c|c|c|c|c|c|c|}
\hline & \multicolumn{4}{|c|}{ Activity during place phase [number of neurons $(\mathrm{E} / \mathrm{I})$ ] } & \multirow{2}{*}{$\begin{array}{l}\text { Spontaneous } \\
\text { firing rate } \\
\text { (spikes/sec) }\end{array}$} & \multirow{2}{*}{$\begin{array}{l}\text { Latency } \\
\text { (msec) }\end{array}$} \\
\hline & Place-differential & Nondifferential & No response & Total & & \\
\hline \multicolumn{7}{|l|}{ Activity during object phase } \\
\hline Go/reward-selective & $22(22 / 0)$ & $12(12 / 0)$ a & $19(15 / 4)$ & $53(49 / 4)$ & $3.54 \pm 0.47$ & $257.5 \pm 10.2^{*}$ \\
\hline Nogo/nonreward-selective & $15(15 / 0)$ & $8(8 / 0)$ & $15(12 / 3)$ & $38(35 / 3)$ & $3.22 \pm 0.53$ & $232.9 \pm 10.1^{*}$ \\
\hline Place-dependent & $8(8 / 0)$ & $0(0 / 0)$ & $0(0 / 0)$ & $8(8 / 0)$ & $2.13 \pm 0.32$ & $231.3 \pm 26.1^{*}$ \\
\hline Nondifferential & $0(0 / 0)$ & $64(28 / 36)$ & $13(6 / 7)$ & $77(34 / 43)$ & $5.44 \pm 0.50$ & $170.0 \pm 12.6$ \\
\hline No response & $13(13 / 0)$ & $1(1 / 0) \quad b$ & - & $14(14 / 0)$ & $2.53 \pm 0.30$ & - \\
\hline Total & $58(58 / 0)$ & $85(49 / 36)$ & $47(33 / 14)$ & $190(140 / 50)$ & $4.11 \pm 0.28$ & $226.0 \pm 6.8$ \\
\hline Spontaneous firing rate (spikes/sec) & $2.57 \pm 0.17$ & $4.67 \pm 0.41$ & $5.00 \pm 0.75$ & $4.11 \pm 0.28$ & & \\
\hline Latency (msec) & $259.1 \pm 19.4^{* *}$ & $167.1 \pm 7.5$ & - & $217.0 \pm 11.9$ & & \\
\hline
\end{tabular}

Each spontaneous firing rate and latency is mean \pm SEM. E, excitation; I, inhibition.

"Both-phase neurons.

${ }^{b}$ Place-phase neurons.

Object-phase neurons.

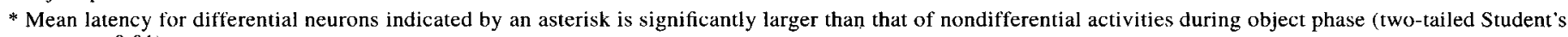
$t$ test, $p<0.01)$.

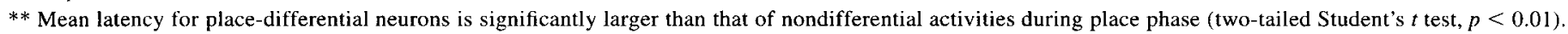

four locations, were compared by one-way ANOVA $(p<0.05)$. Comparison of responses between two possible pairs was made by the Newman-Keuls method of multiple comparisons $(p<0.05)$. The responses to place were considered to be significant only if the following two conditions were satisfied: (1) excitatory or inhibitory responses to a given place were significant compared to the control phase, and (2) there was significant difference between the response to a given place and the smallest response to at least one of the remaining three places in the post hoc test of ANOVA. Place-differential neurons were defined as those that had significant responses to at least one place, but not to more than three places.

Ncural responses to objects were analyzed in three ways. First, responses to each of four objects in the PGN task were compared by one way ANOVA (analysis I) regardless of place or response/reinforcement contingency. Second, responses to objects in four places were compared by one way ANOVA (analysis II) regardless of the kinds of objects. Third, responses to each object in the go/reward and no-go/nonreward trials in the PGN and AGN tasks, and in the go/reward and no-go/ reward trials in the SGN task were compared by Mann-Whitney $U$ test (analysis III). Each criterion level for significance was $p<0.05$. The neurons that responded significantly in analysis III were designated contingency-differential neurons, and those that responded significantly in analysis II, but not in analysis III, were designated place-dependent neurons. The nondifferential neurons were those that had no differential responses in analyses I, II, and III.

The response latency of each neuron that responded during a con ditioned sensory stimulation period was defined as the time between the computer-generated, synchronizing trigger signal that indicated the onset of sensory stimulation and the time when the firing rate exceeded $\pm 2.0 \mathrm{SD}$ from the mean spontaneous firing rate. Differences in spontaneous firing rates and response latencies of differential and nondifferential neurons were determined by two tailed Student's $t$ test $(p<$ 0.05 ).

The EOG records (time constant, DC) were prepared through Ag$\mathrm{AgCl}$ electrodes on the lateral edges of the eyes. The EOG was calibrated by having the monkey look at LED lamps located in specific positions. During the task, zero (center) position of the EOG was verified from time to time when the monkey looked at the task object in the center of the field. Correlation between eye movement and neural activity was analyzed, off line, by comparing the spike counts for 0.3 sec before and after eye movement during the task by paired $t$ test $(p$ $<0.05)$.

Ilistology. After the last recording session, several small marking lesions were made around the septal nuclei by passing 20-30 $\mu \mathrm{A}$ of anodal current for $40 \mathrm{sec}$ through an electrode placed stereotaxically and monitored by $x$-ray. After that, each animal was deeply anesthetized with an overdose of sodium pentobarbital $(50 \mathrm{mg} / \mathrm{kg}$, i.m.) and perfused transcardially with $0.9 \%$ saline followed by $10 \%$ buffered formalin. The brains were removed and cut into $50 \mu \mathrm{m}$ sections through the septal nuclei. Sections were stained with cresyl violet, and sites of electrical lesions were determined microscopically. The location of each recording site was then calculated from the stereotaxic coordinates of the recording sites and the marking lesions. The positions of the septal nuclei and of the recording electrodes were checked by x-ray photography during the experiments, and these photographs were compared with those of the marking electrodes to verify the calculated recording sites.

Classification and terminology of the septal nuclei were based on the atlas of Kusama and Mabuchi (1970) for Macaca fuscata. In the present study, the lateral nucleus included the lateral and dorsal septal nuclei.

\section{Results}

Analysis of the EOGs indicated no difference in eye movement at any of the four locations, and no correlation between neural responses and eye movements (see below). A total of $142 \mathrm{elec}-$ trode penetrations were made into the septal nuclei of two monkeys in these experiments. The activity of 430 neurons was recorded from these penetrations during performance of the PGN task. Of these neurons, 14 (all excited) responded in the place phase but not in the object phase (place-phase neurons), 47 (33 excited, 14 inhibited) responded in the object phase but not in the place phase (object-phase neurons), and 129 (93 excited, 36 inhibited) responded in both place and object phases (both-phase neurons). In the present paper, we analyzed the responses of these 190 visually responsive neurons (140 excited, 50 inhibited) during the place and/or object phases (Table 1).

\section{Place-differential responses in the place phase}

Responses during the place phase were significantly place-differential in 58 ( 13 place-phase and 45 both-phase) neurons (all excited). Responses of the remaining 85 neurons were nondifferential (Table 1). The spontaneous firing rates of place-differential neurons were $0.2-6.0$ spikes/sec $(2.57 \pm 0.17$ spikes $/ \mathrm{sec}$, mean $\pm \mathrm{SEM}, n=58$ ), and those of nondifferential neurons were $0.6-19.3 \mathrm{spikes} / \mathrm{sec}(4.67 \pm 0.41 \mathrm{spikes} / \mathrm{sec}, n=85)$. The latencies for the place-differential responses were $100-1000$ msec $(259.1 \pm 19.4 \mathrm{mscc}, n=58)$, and thosc for the nondifferential responses were $50-280 \mathrm{msec}(167.1 \pm 7.5 \mathrm{msec}, n=$ 


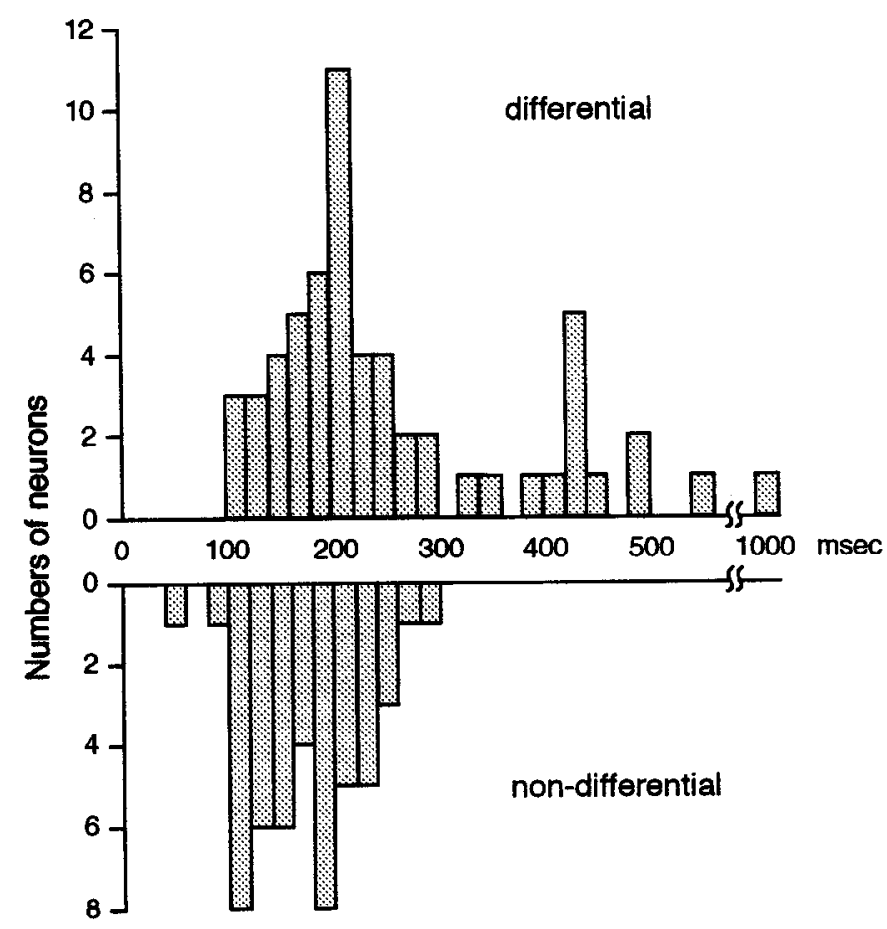

Figure 3. Latency of differential and nondifferential responses during the place phase. Mean $( \pm$ SEM) of the latency was $259.1+19.4 \mathrm{msec}$ in the place-differential neurons and $167.1 \pm 7.5 \mathrm{msec}$ in the nondifferential neurons.

49) (Fig. 3). Differences in response latencies between these 2 categories were statistically significant (two tailed Student's $t$ test, $p<0.01$ ).

Responses of a typical place-differential neuron are shown in Figure 4 . In each recording session, 16 place-object combinations were tested in 24 or more trials in pseudorandom order. However, the results were rearranged for presentation as in Figure $4 A$, for example, and in other figures to allow more convenient comparisons. This neuron responded during the place phase only when the cab was located in place I, but not during the object phase in the PGN task. There were no differences in the spontaneous firing rates during the control phase among the four cab locations, and this was true of all the other place-differential neurons. Some eye movements were observed during the place phase, and rarely in the object phase (Fig. $4 A$ ). No specific eye movement could be related to a specific place. Eye movement during the place phase in the present study seemed to be consistent with a previous behavioral study in which natural scanning eye movement of the monkey was reported in viewing complex natural scenes (Burman and Segraves, 1994). Perievent time histograms before and after the onset of saccades indicated no correlation between eye movement and the neural activity recorded here (Fig. $4 B$ ). Of the 143 place-phase and both-phase ncurons, 78 were analyzed in this way, and no correlation between neural activity and eye movement was found.

The mean magnitudes of responses during the place phase are presented in Figure $4 C$. To analyze independence of place-differential responses to a specific distant cue, this neuron was tested by a change in the environment in which a table in front of the place II was moved to the front of place I. Figure $4 D$ shows the results of this test for blocks of each three trials in place I before (pre) and after (post) moving the table, and after returning the table to its original position. After shifting the table, responses of this neuron in place I decreased transiently in the first several trials but recovered later to the pretest level. After returning the table to its original position, the neuron continued to respond in place I. Similar results were obtained for two of four place-differential neurons tested by this probe test and the place-differential responses of the other two neurons were not affected by the table shift.

Figure 5 illustrates results of post hoc analyses (NewmanKeuls method of multiple comparisons) of place-differential neurons. As shown in Figure 5 (also see Figs. 4, 7, 9, 11), 27 place-differential neurons responded more in one place, 23 responded more in two places, and 8 responded more in three places than in the remaining place(s). Neurons that were activated in two places prefcrred right-left more than front-back, and had no preference for any diagonal positions.

\section{Differential responses in the object phase}

For each object- and both-phase neuron $(n=176)$, the objectphase responses were evaluated by ANOVA for object selectivity, regardless of the response/reinforcement contingency. Of these neurons, only four were object differential. However, when responses to the four objects in the PGN task were analyzed with respect to the response/reinforcement contingency (Table 1), 91 (34 of 47 object-phase; 57 of 129 both-phase) neurons exhibited contingency-differential (i.e., go/reward- and no-go/ nonreward-selective) responses to one or more objects. The others were place-dependent $(n=8)$ (see below in detail) or nondifferential ( $n=77$ ) (Table 1). Response latencies in the object phase for the differential neurons (go/reward selective, no-go/ nonreward selective, and place dependent) were $130-170 \mathrm{msec}$ $(245.7 \pm 7.1 \mathrm{msec}, n=91)$, and those for nondifferential neurons, $60-290 \mathrm{msec}(170.0 \pm 12.6 \mathrm{msec}, n=32)$ (Fig. 5). The difference in the latency between differential and nondifferential responses to the objects was statistically significant (two tailed Student's $t$ test, $p<0.01$ ).

\section{Place-dependent responses in the ohject phase}

Eight neurons were more active when the monkey was in a particular place(s), not only in the place phase but also in the object phase, regardless of object meaning. Figure 7 shows an example of this type of response for one neuron. The activity increased during both place and object phases only when the monkey was located in place I or IV in the PGN task (Fig. 7A). Analysis by ANOVA indicated that responses to places I and IV were significant (Fig. $7 B$ ). During the object phase, there were no differences in responses to objects between go and nogo trials in any of the four places (the Mann-Whitney $U$ test, $p$ $>0.05$ ) (Fig. $7 C$ ). However, the responses during the object phase were significantly larger in places I and IV (indicated by $*^{*}$ in Fig. $7 C$ ) when data was analyzed, regardless of the response/reinforcement contingency or features of the objects.

The neuron in Figure 7 was also tested with a reversed object place version of the PGN task (ROP). The task performance in both the PGN and ROP during the recording session of this neuron is shown in Figure 8 . The correct choice fell to the chance level in both go and no-go ROP trials. The neural responses during the first $4 \mathrm{sec}$ after the start of each trial in particular places ( $I$ and IV in this case) were diminished if visual information about spatial location was not available in the ROP (Fig. $7 D$ ). In the object phase, the place-dependent response depicted in Figure $7 C$, which was evident in places $I$ and IV in 
A

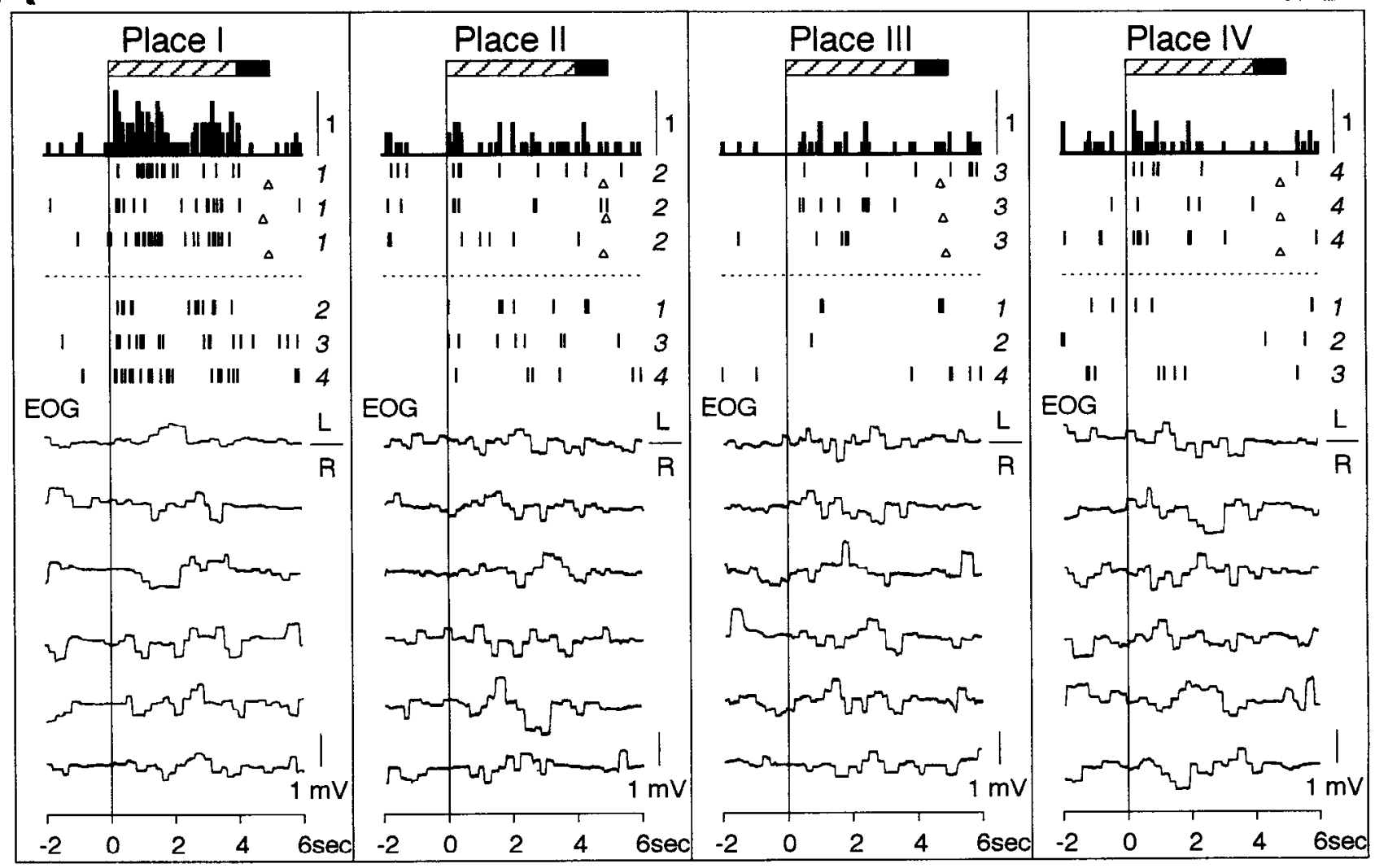

B

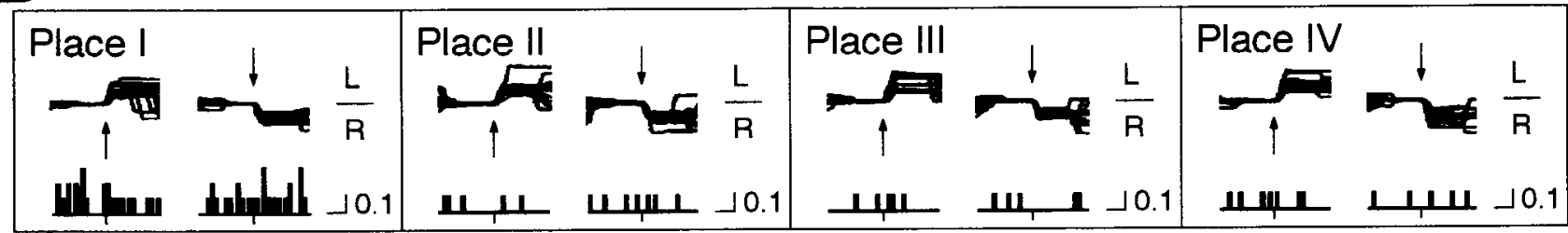

C
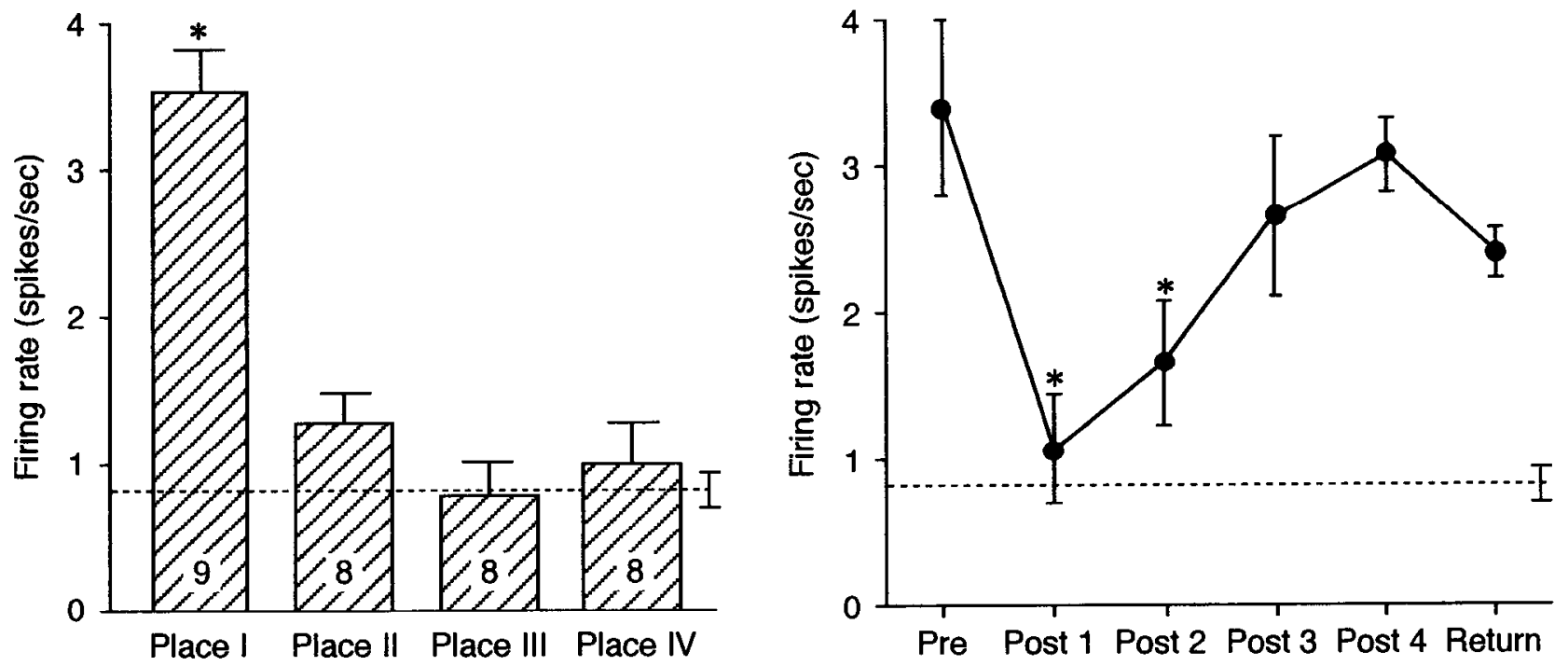


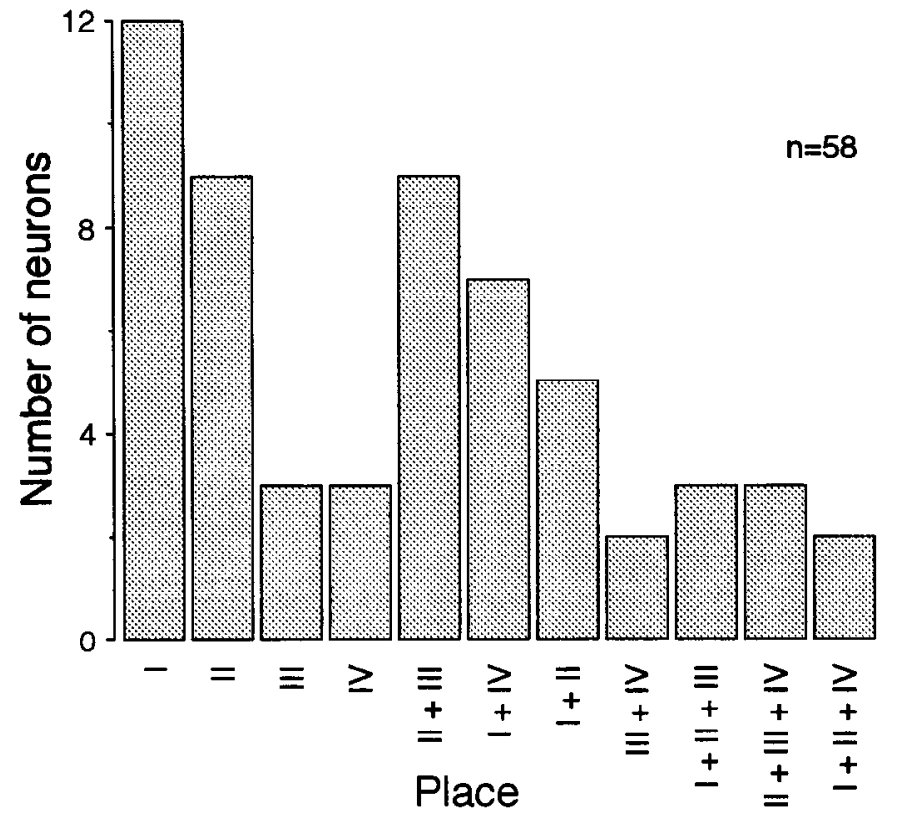

Figure 5. Pattern of place-phase responses of all place-differential (whether place-phase or both-phase) neurons $(n=58)$. On the abscissa are Places $I-I V$ in which significant responses were elicited compared to the control phase, and responses larger than any evoked in at least one other place.

the PGN task, also disappeared when the monkey could not see the environment outside of the cab before object discrimination in the ROP (Fig. $7 F$ ). These same results were recorded from all of four neurons, including this neuron, with place-differential response in the place phase of the PGN task, and which could be tested in the ROP.

In three neurons that exhibited contingency-differential responses in the object phase (see below), responses to objects also decreased in the ROP version. On the other hand, responses of two neurons with nondifferential response in both the place and object phases when tested by ROP were not affected by reversing the sequence of these two phases (not shown).

\section{Contingency-differential responses in the object phase}

Of 91 contingency-differential neurons, 53 go/reward-selective neurons responded more in go trials, and 38 no-go/nonrewardselective ncurons responded more in no-go trials. A typical go/ reward-selective neuron is shown in Figure 9. This neuron responded in place III during the place phase, and to objects indicating go/reward contingency regardless of place (Fig. 9A).

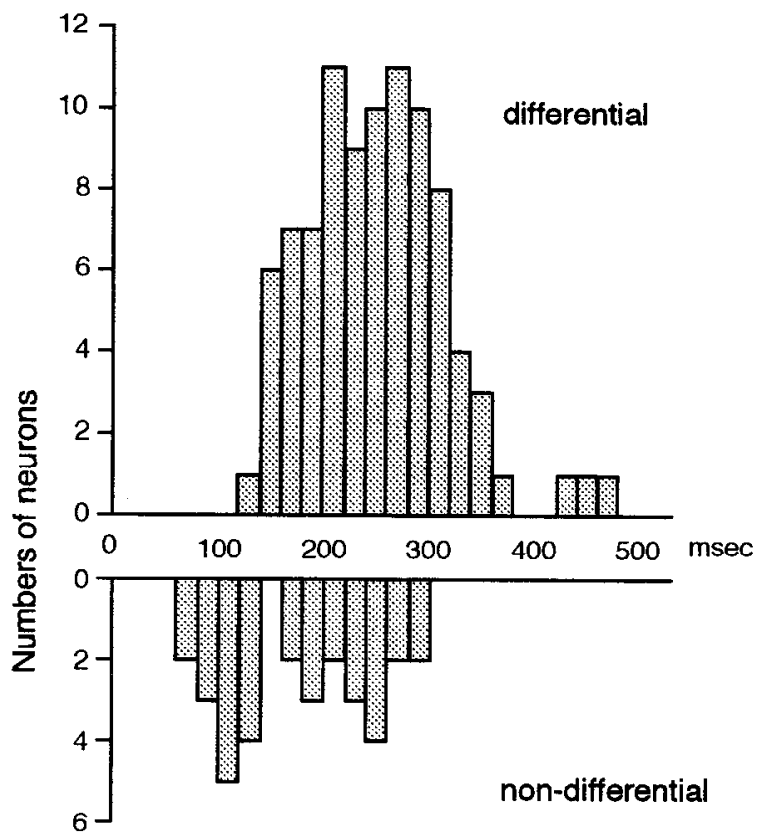

Figure 6. Latency of differential and nondifferential responses during the object phase. Mean $( \pm$ SEM) of the latency was $245.7 \pm 7.1 \mathrm{msec}$ in the differential neurons (go/reward selective, no-go/nonreward selective, and place-dependent) and $170.0 \pm 12.6 \mathrm{msec}$ in the nondifferential neurons.

Analysis by ANOVA indicated that the place III responses were significant (Fig. 9B). This neuron response was significantly stronger during the object phase when the objects were rewarding in go trials based on the place-object relations in the PGN task (Fig. 9C, left). A typical no-go/nonreward-selective neuron is shown in Figure 10. This neuron did not respond during the place phase (Fig. 10A). During the object phase, this neuron differentially responded to the object when it indicated nonreward contingency with no-go response in the PGN task (Fig. $10 A, B$, left).

The contingency-differential response did not always appear for all four objects used in the PGN task. An example is depicted in Figure 11. In the place phase, this neuron had a place-differential response with preference for place III (Fig. $11 A, B$ ). In the object phase, this neuron showed contingency-differential responses only to object 3 (Fig. 11C). Of 91 contingency-differential neurons (53 go/reward-selective; 38 no-go/nonreward-selective), 32 go/reward-selective and 20 no-go/nonrewardselective neurons demonstrated contingency-differential re-

$\leftarrow$

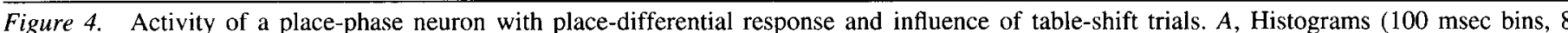

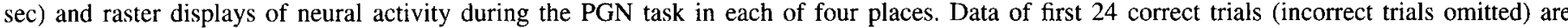

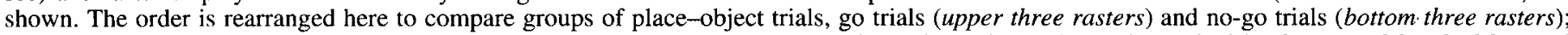

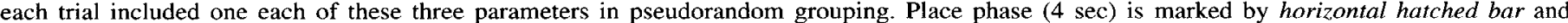

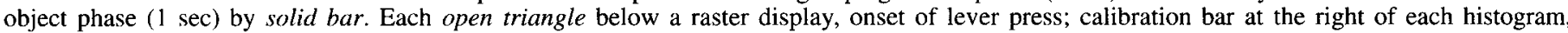

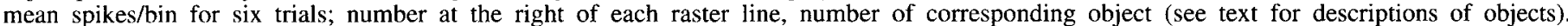

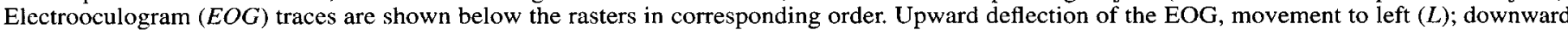

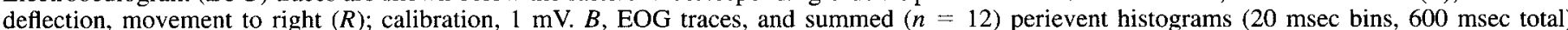

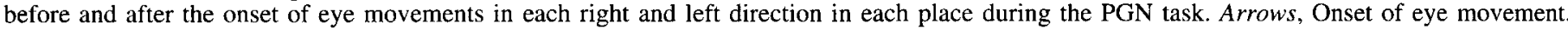

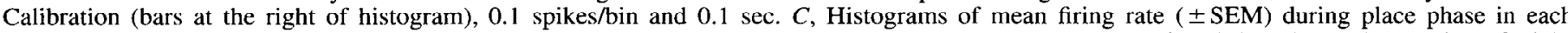

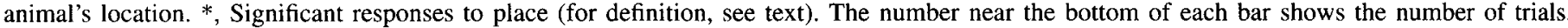

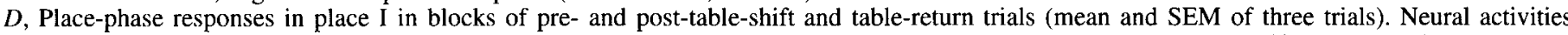

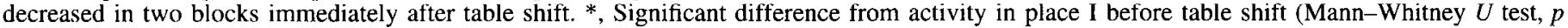
$<0.05$ ). Broken lines and error bars in $C$ and $D$, mean spontaneous firing rate and SEM during control phase, respectively. 

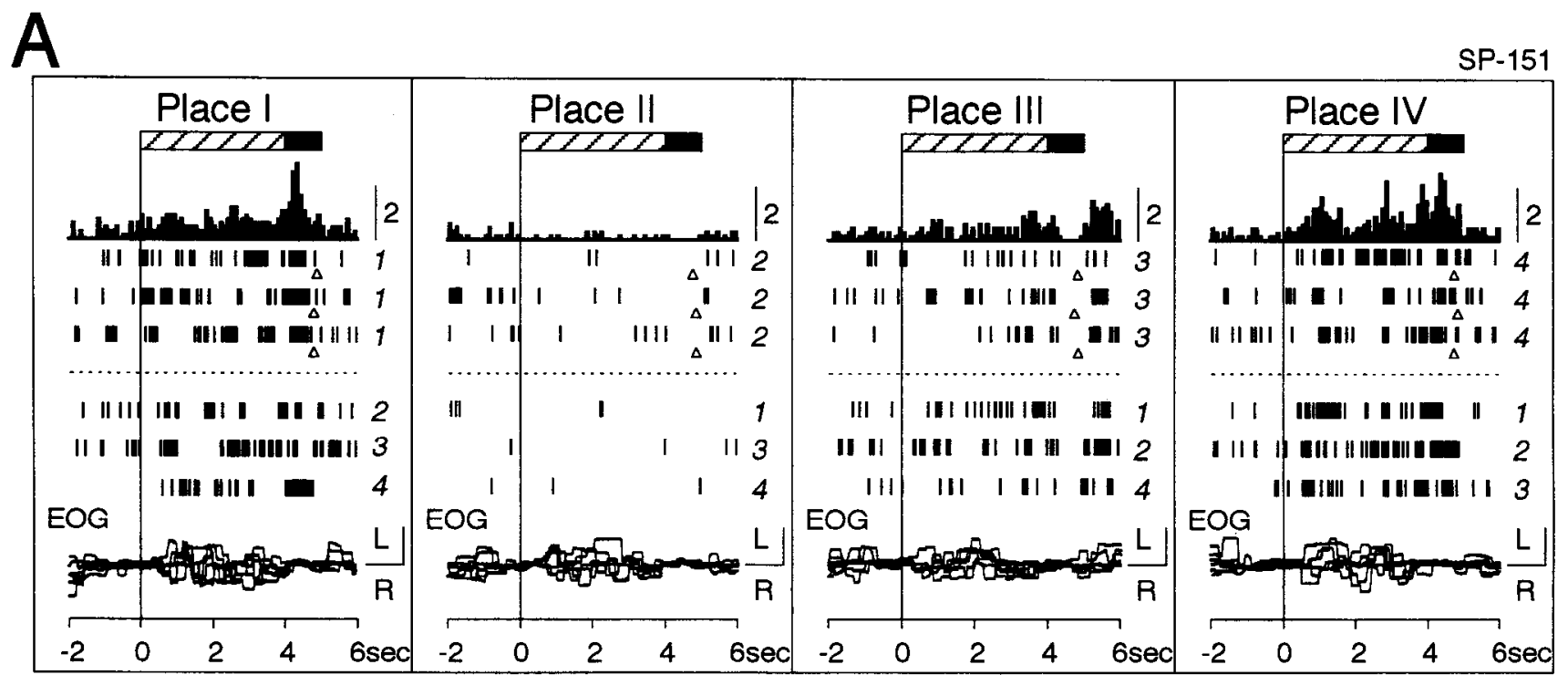
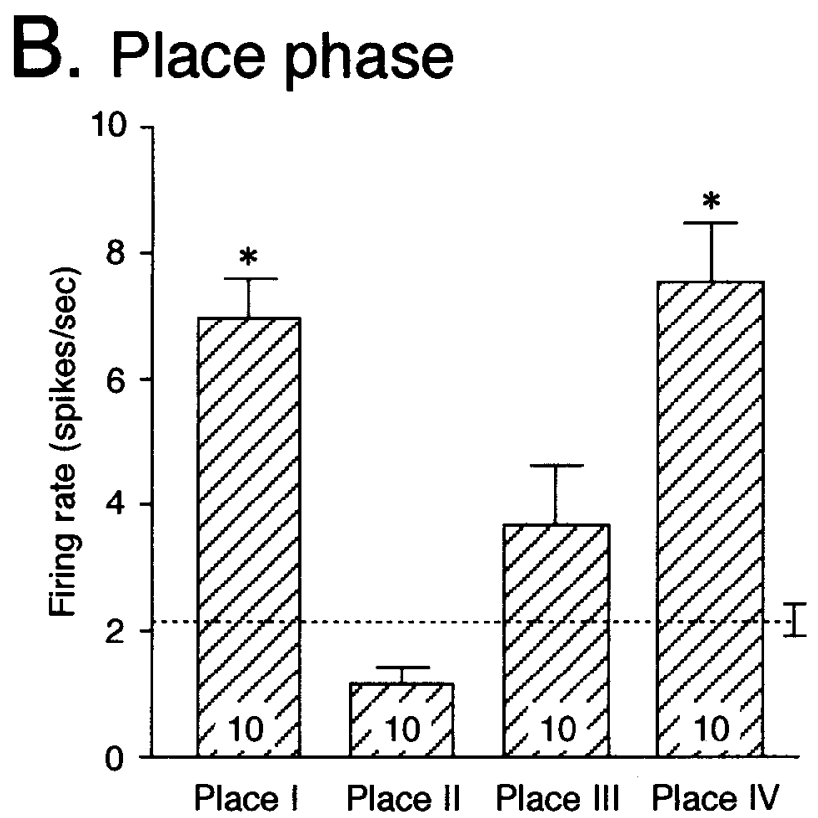

\section{Pre-object phase (ROP)}

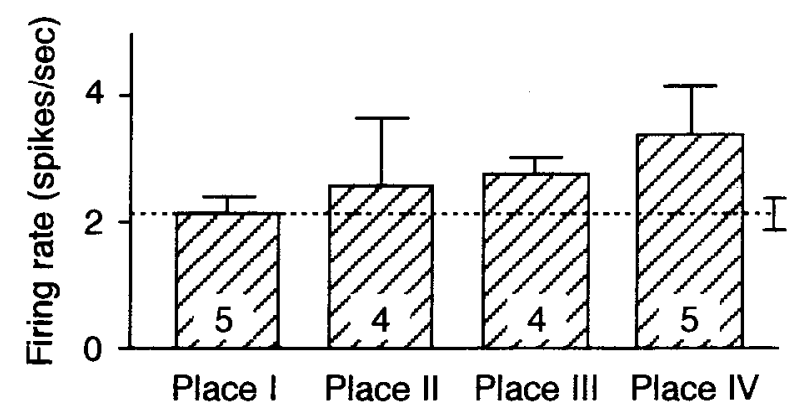

\section{Object phase}

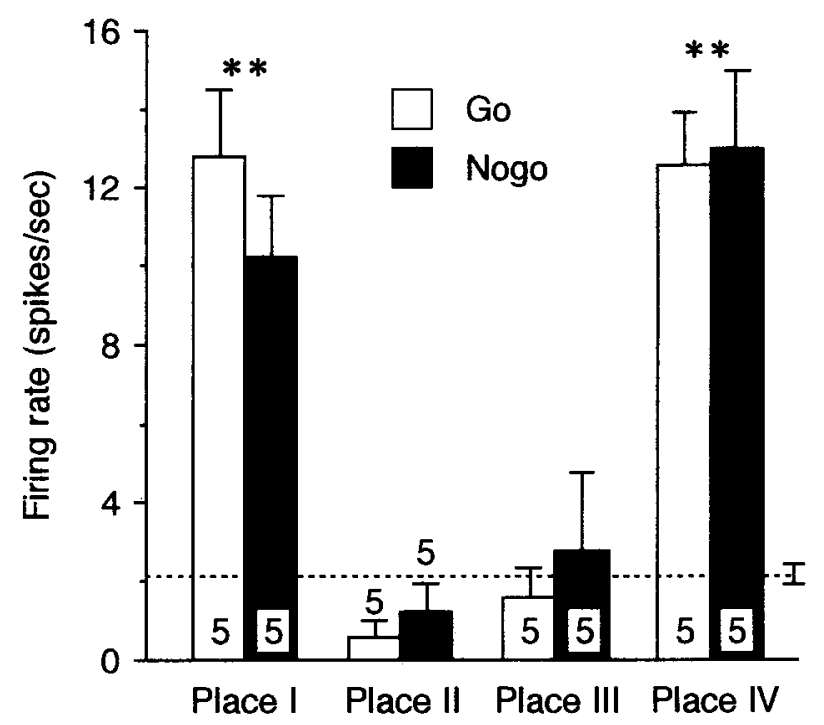

E. Object phase (ROP)

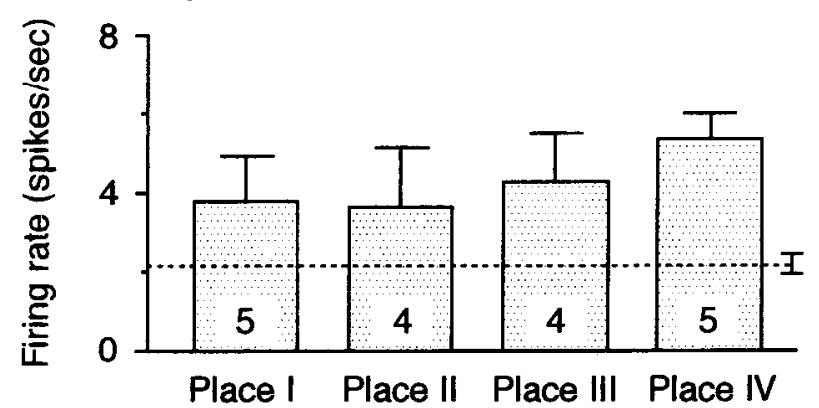

Figure 7. Activity of a both-phase neuron with place-dependent response in the original place-dependent go/no-go (PGN) task ( $A-C)$ and influence of reversing the sequence of place and object phases (ROP version) on neural responses $(D, E)$. A, Histograms and raster displays show differential responses only during the place and object phases and these in Places $I$ and $I V$ only. Other descriptions as for Figure 4 except that EOG traces are superimposed. $B$, Place-phase responses (mean \pm SEM) for four places. Other descriptions as for Figure $4 C$. $C$, Histograms of mean firing rate $( \pm$ SEM) during object phase in each place for go and no-go trials. There were no differences between go and no-go trials in responses to objects in each of four places (the Mann-Whitney $U$ test, $p>0.05$ ). **, Significant difference in responses to objects among the four places when responses to objects were analyzed regardless of go and no-go trials (ANOVA, $p<0.01$ ). $D$ and $E$, Responses in the pre-object phase $(D)$ and object phase $(E)$ of ROP in four places. No significant difference was revealed by ANOVA $(p>0.05)$. Other descriptions as for Figure 4. 


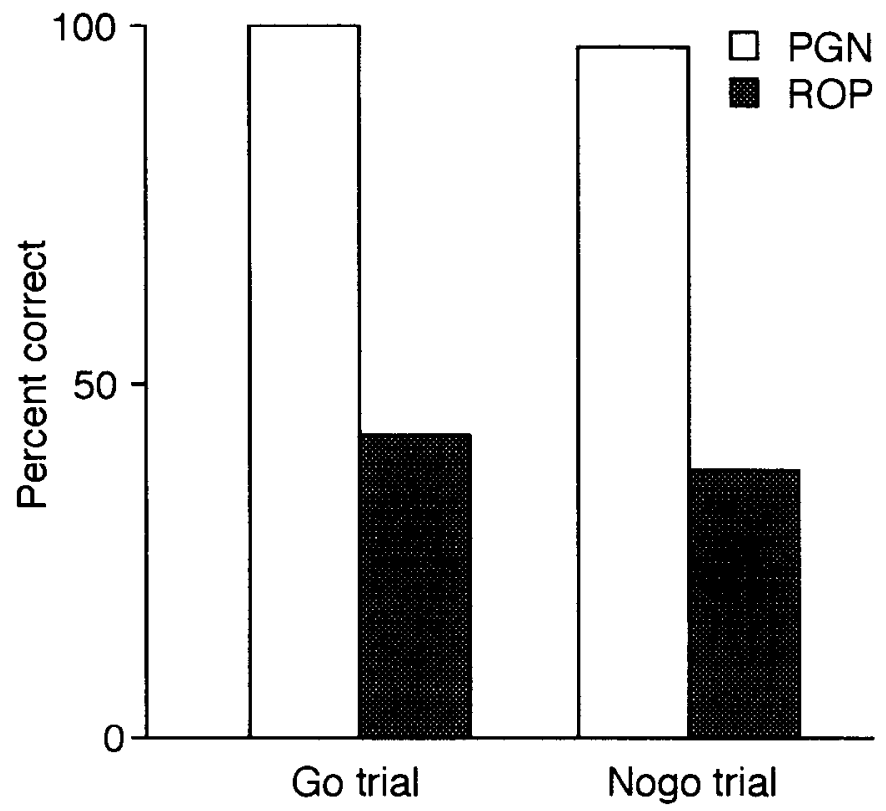

Figure 8. Influence of reversing the sequence of place and object phases (ROP version) on task performance. The monkey's performance in the PGN task and its ROP version during the neural recording shown in Figure 7 are compared for go and no-go trials.

sponses to some but not all of the four objects. The remaining 21 go/reward-selective and 18 no-go/nonreward-selective neurons responded differentially to all four objects (Fig. 12).

There werc some relations betwecn the numbers of objects to which the neurons showed contingency-differential responses, and responsiveness in the place phase. Among the 39 neurons that emitted contingency differential responses to all objects in the PGN task (21 go/reward-selective; 18 no-go/nonreward-selective), only 8 (4 go/reward-selective; 4 no-go/nonreward-selective) were place-differential responsive in the place phase (Fig. 12), like the neuron in Figure 9. Annong the 52 neurons that emitted contingency-differential responses to some but not all object(s) in the PGN task (32 go/reward selective, 20 no-go/ nonreward selective), 29 (18 go/reward selective, 11 no-go/nonreward selective) were place-differential responsive in the place phase (Fig. 12), like the neuron in Figure 11. This proportion of place-differential responses $(29 / 52,55.8 \%)$ was higher than that of the neurons with contingency-differential responses to all objects $(8 / 39,20.5 \%)$ (Fisher's exact probability test, $p<0.01$ ).

\section{Asymmetrical go/no-go (AGN) task}

To test whether or not contingency-differential response during the object phase in the PGN task depended on conditional placeobject relations, 72 neurons ( 37 of 53 go/reward-selective; 35 of 38 no-go/nonreward-selective) were tested in the unconditional place-independent AGN task. Of these 72 neurons, $22 \mathrm{go} /$ reward-selective and 21 no-go/nonreward-selective neurons responded differentially only in the PGN task in which discrimination of conditional place-object relations was required, but did not respond differentially to go/reward and nogo/nonreward objects in the AGN task (PGN-specific) (Fig. 12). Typical examples are shown in Figures 9 and 10. The go/rewardselective neuron in Figure 9 did not respond differentially to a go/reward ubject (white objecl) in the AGN task (Fig. 9C), and the no-go/nonreward-selective neuron in Figure 10 did not re- spond to a no-go/nonreward object (yellow object) in the AGN task (Fig. 10B). The remaining 29 neurons ( 15 go/reward selective, 14 no-go/nonreward selective) were contingency-differential responsive in both the AGN and the PGN tasks (PGN nonspecific).

The PGN specificity was significantly related to the number of objects to which the neurons showed contingency-differential responses in the PGN task. Of 39 neurons with contingencydifferential responses to some but not all object(s) tested by the AGN task (22 go/reward selective, 17 no-go/nonreward selective), 32 (17 go/reward selective, 15 no-go/nonreward selective) were PGN specific (Fig. 12). This proportion of the PGN-specificity $(32 / 39,82.1 \%)$ was significantly higher than that of the PGN-specific neurons with contingency-differential responses to all objects $(11 / 33,33.3 \%)$ (Fisher's exact probability test, $p<$ $0.05)$.

\section{Symmetrical go/no-go (SGN) task}

Of the 15 PGN-nonspecific go/reward-selective neurons, 9 were further tested in the SGN task, in which go and no-go responses were both reinforced, to determine if this contingency-differential response reflected behavior (go response) or reward availability. Figure 13 shows the results for two different go/rewardselective neurons. Both responded strongly during the object phase when the objects were rewarding, depending on their place-object relations in the PGN task (Fig. 13A,B). The neuron in Figure $13 A$ responded to the object indicating no-go/reward contingency as well as the object indicating go/reward contingency in the SGN task (reward-related neuron). On the contrary, the neuron in Figure $13 B$ did not respond to the object indicating no-go/reward contingency, but responded to the object indicating go/reward contingency in the SGN task (go-related neuron). Of the nine go/reward-selective neurons that could be tested on the SGN task, seven were reward related, and two were go related (Fig. 12).

Of the 14 PGN-nonspecific no-go/nonreward-selective neurons, 12 were similarly tested with the SGN task. All of these 12 neurons were concluded to be nonreward-related neurons, since they did not respond to the object indicating no-go/reward contingency in the SGN task (Fig. 12). A typical nonrewardrelated neuron is shown in Figure 14. This neuron responded differentially during the object phase when nonreward contingency with no-go response was indicated in the PGN (Fig. 14A) and AGN (Fig. 14B) tasks. In the SGN task, the neuron did not respond differentially to two objects that indicated reward contingency with go or no-go response (Fig. 14A).

Thus, most of the PGN-nonspecific neurons $(19 / 21,90.5 \%)$ which could be tested in the SGN task were related to the reward/nonreward contingency, rather than to the response contingency.

\section{Influence of extinction and relearning}

To characterize the reward/nonreward contingency related responses mentioned above, effects of direct manipulation of reward contingency were analyzed. Of the 12 nonreward-related neurons, 4 were further tested with extinction and reassociation of reward. Among these four, plastic change of neural response was demonstrated by two neurons, whereas the responses of the other two neurons were not affected by extinction. The neuron depicted in Figure 14 is an example of such neurons with plastic change. Aclivity of this neuron during presentation of the white object (usually rewarding) in the AGN task was 


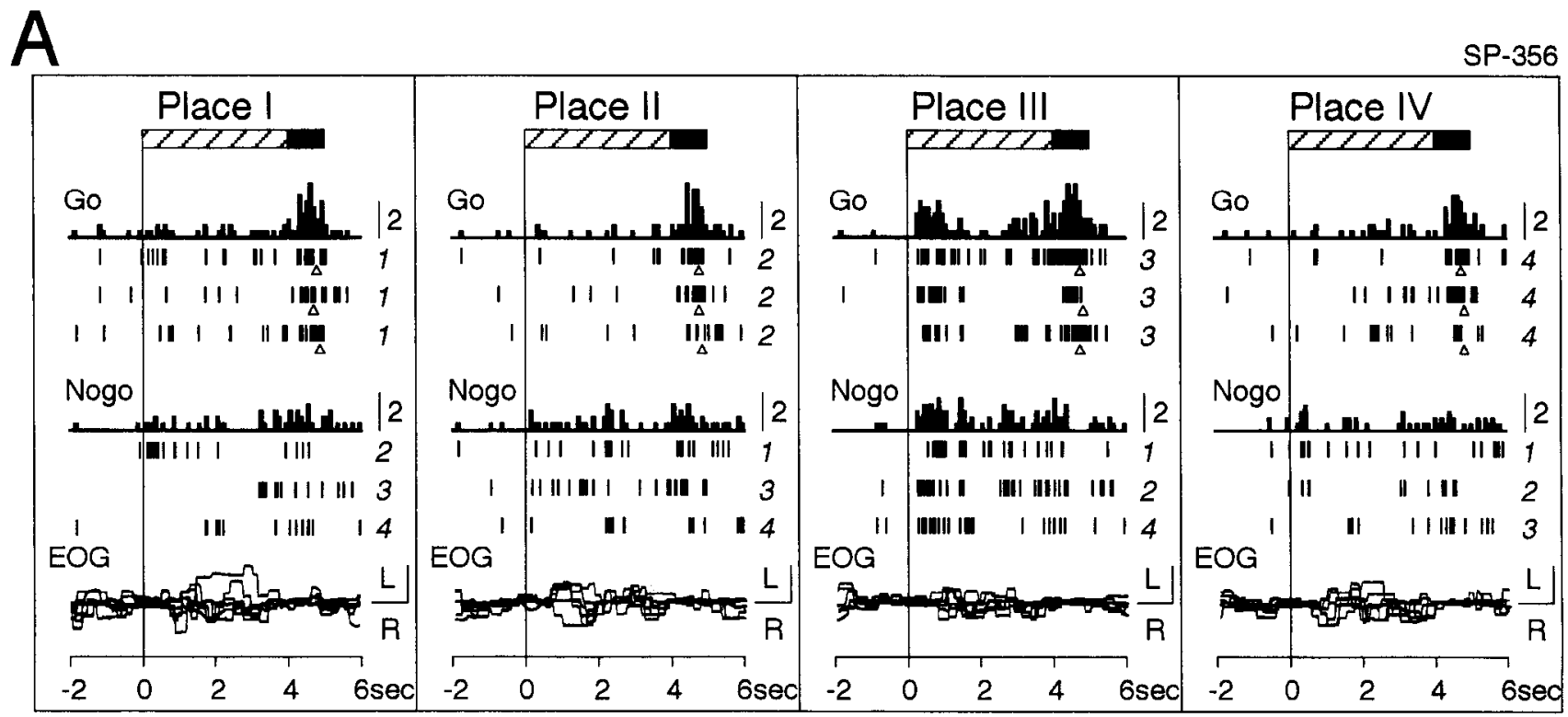

B. Place phase

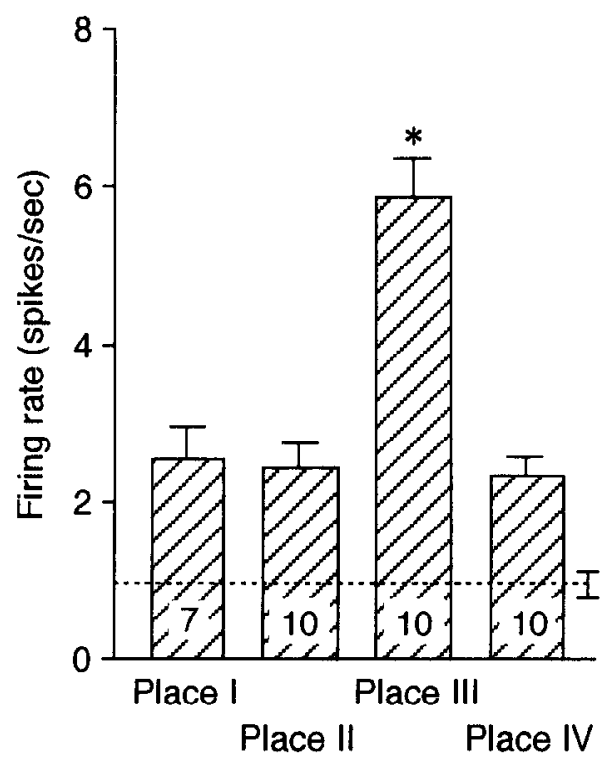

C. Object phase

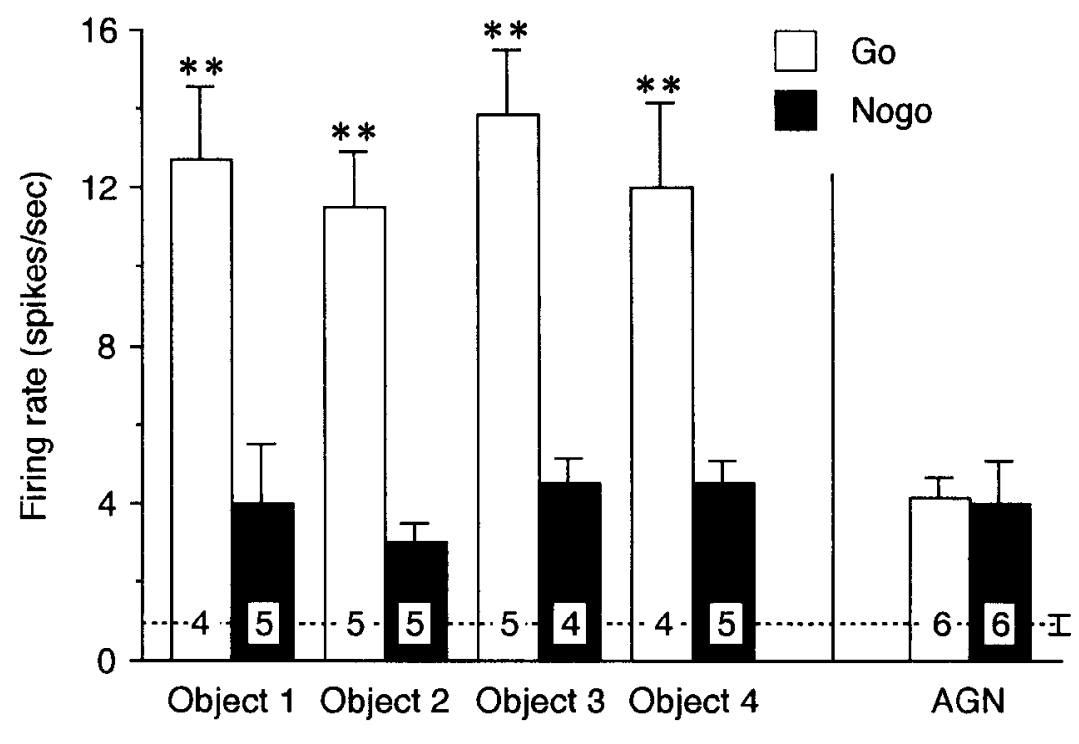

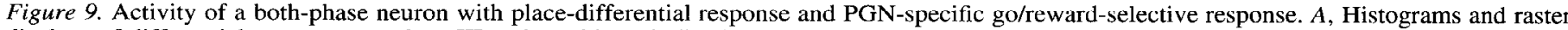

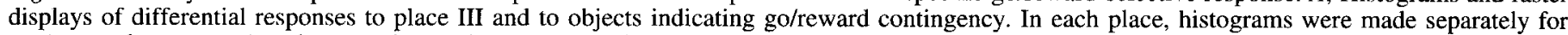

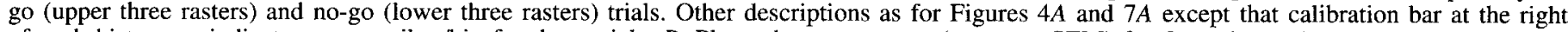

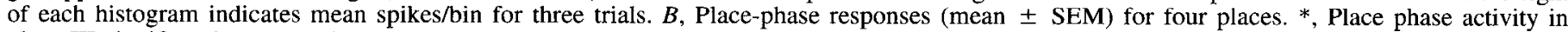

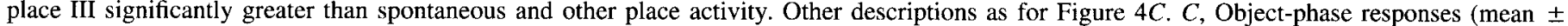

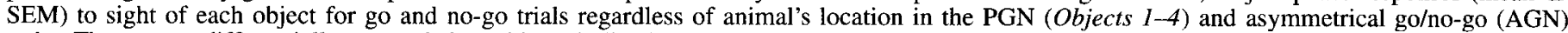

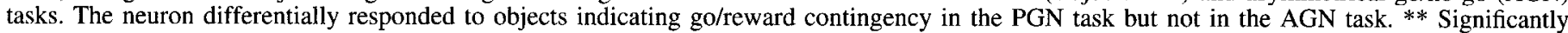

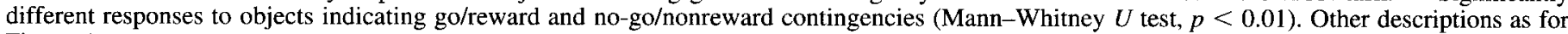
Figure 4.

analyzed during the course of extinction and subsequent relearning (Fig. 14B-D). Before extinction trials, the neuron differentially responded stronger to the yellow object indicating nonreward contingency than to the white object indicating reward contingency (yellow and white object trials were presented at random before extinction, but rearranged in Fig. $14 C, D)$. After several nonreinforced extinction trials with the white object, the monkey learned to withhold the lever press. The response during presentation of the white object became as strong as that during presentation of the nonrewarding ycllow object. During the relearning trials, this response gradually decreased to the pretest level (Fig. 14D). Mean response magnitudes in the block of three trials during presentation of white object are shown in Figure $14 B$ in comparison to the responses in the ordinary AGN task.

Of the seven reward-related neurons, three were similarly testcd with extinction and relearning. The responses of all of these three to the rewarding white object in the AGN task disappeared 


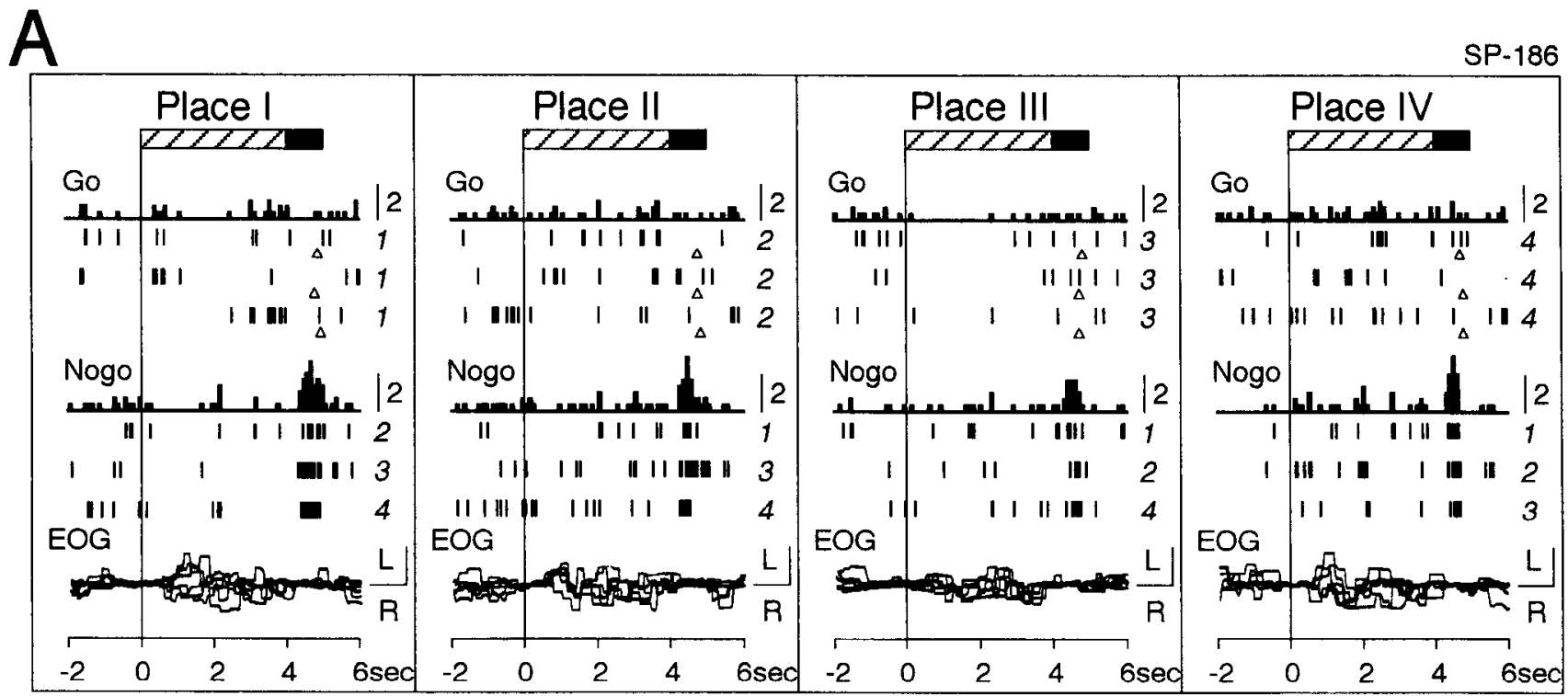

\section{B. Object phase}

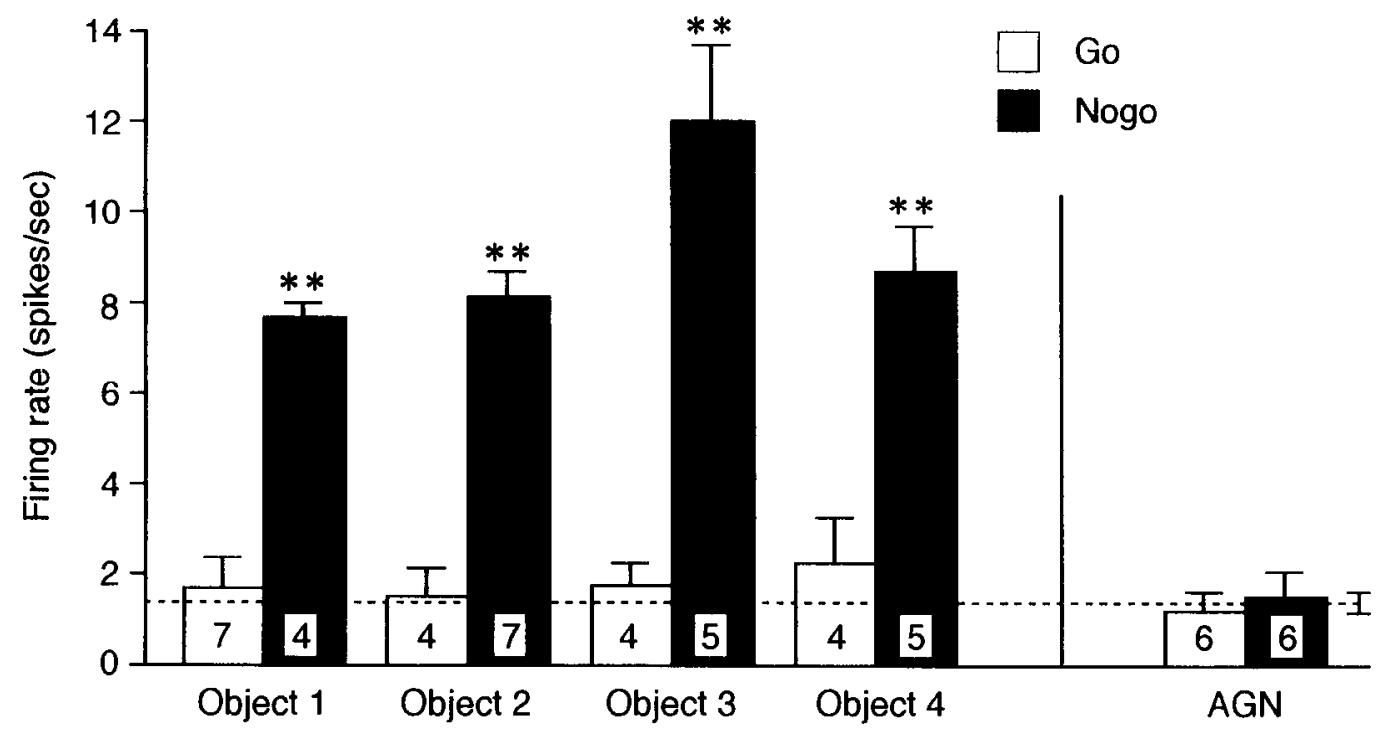

Figure 10. Activity of an object-phase neuron with PGN-specific no-go/nonreward-selective response. A, Histograms and raster displays of differential responses to objects indicating no-go/nonreward contingency. In each place, histograms were made separately for go and no-go trials. Other descriptions as for Figures $4 A$ and $9 A . B$, Object-phase responses (mean \pm SEM) to sight of each object for go and no-go trials regardless of animal's location in the PGN (Objects $1-4$ ) and asymmetrical go/no-go $(A G N)$ tasks. Neuron was significantly more active when object indicated no-go/nonreward contingency in the PGN task but not in the AGN task. **, Significantly different responses to objects indicating go/reward and no-go/nonreward contingencies (Mann-Whitney $U$ test, $p<0.01$ ). Other descriptions as for Figure 4.

after extinction and quickly reappeared after relearning (not shown).

\section{Locations of neuron types}

Recording sites of all the neurons tested are shown in Figure 15. Of the neurons recorded 300 were in the lateral septal nuclei, 120 were in the medial septal nuclei, and 10 were in the nuclei of the diagonal band of Broca. The visually responsive neurons were intermingled in all of the regions.

Figure 16 shows the distribution of various neuron types based on responses in the PGN task. Of the 91 contingencydifferential neurons (53 go/reward selective, 38 no-go/nonre- ward selective), 76 and 15 were located in the lateral and medial septal nuclei, respectively. The proportion of contingency-differential neurons in the lateral septal nuclei $(76 / 300,25.3 \%)$ was higher than that in the medial septal nuclei $(15 / 120,12.5 \%)$ (Fisher's exact probability test, $p<0.01$ ). Nondifferential neurons were distributed more evenly. Of 77 nondifferential neurons, $46 / 300(15.3 \%)$ were in the lateral, and $29 / 120(24.2 \%)$ were in the medial septal nuclei. This difference in proportions of nondifferential neurons was not significant (Fisher's exact probability test, $p>0.05$ ). The two remaining neurons were located in the nuclei of the diagonal band of Broca. $\Lambda$ ll placedependent neurons were located in the lateral septal nuclei. 
A

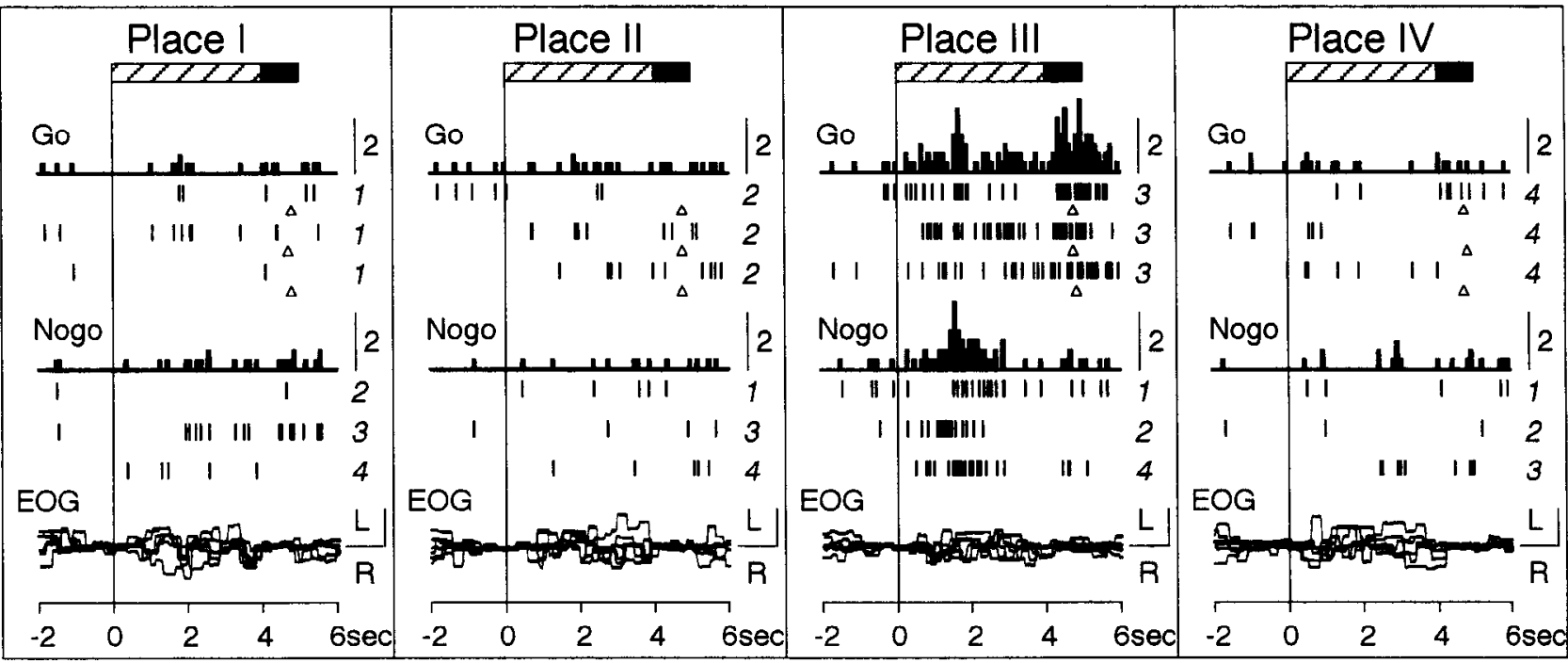

\section{B. Place phase}

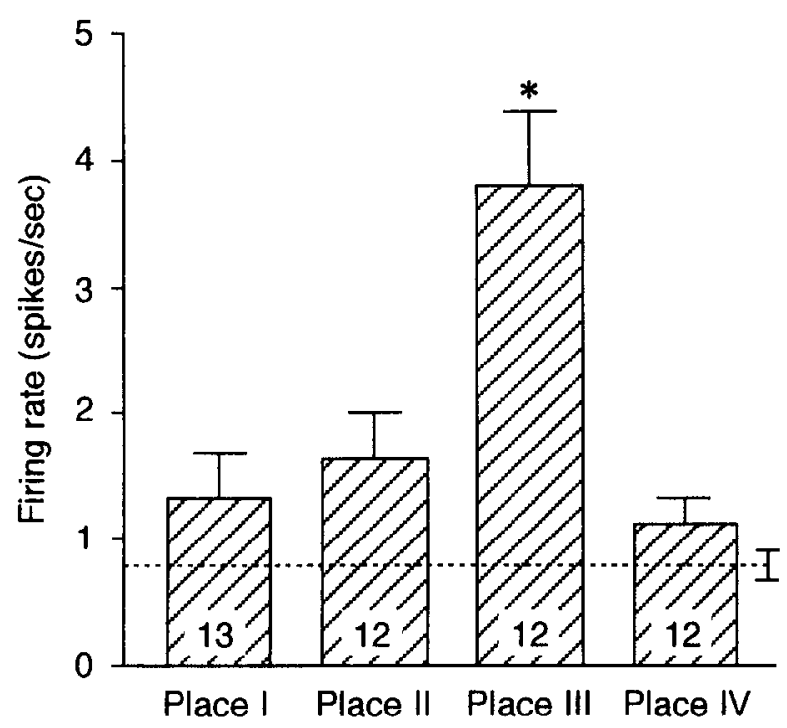

\section{Object phase}

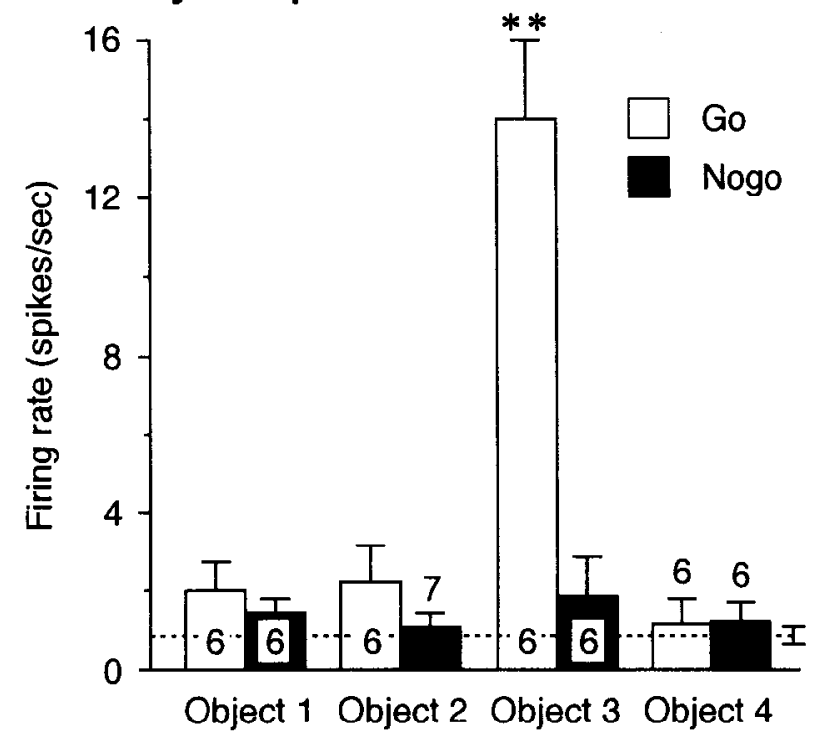

Figure 11. Activity of a both-phase neuron with place-differential response $(A)$ and go/reward-selective response only to Object $3(B)$. $A$, Histograms and raster displays of differential responses to Place $I I I$ and to Object 3 only when it indicated go/reward contingency. Other descriptions as for Figures $4 A$ and $9 A$. B. Activity during place phase (mean \pm SEM) for four places. $C$, Object-phase responses (mean \pm SEM) to sight of each object for go and no-go trials regardless of animal's location in the PGN task. **, Significantly different responses to objects indicating go/ reward and no-go/nonreward contingencies (Mann-Whitney $U$ lest, $p<0.01$ ). Other descriptions as for Figure 4.

Distributions of the various neuron types based on their responses in the PGN, AGN, and SGN tasks are shown in Figure 17. Many of the contingency-differential neurons (PGN-specific, reward-related, go-related, and nonreward-related) were densely packed in the dorsal and intermediate parts of lateral septal nuclei and some PGN-specific neurons were in the medial septal nuclei. Most neurons with placedifferential responses were located in the area dorsal to the anterior commissure in the middle planes (A24, A23, and A22).

\section{Discussion}

The present study demonstrated cognitive correlates of neural responses in the monkey septal nuclei during place-object association learning, which requires discrimination of both spatial and conditional relations. Fifty-eight of 430 neurons responded differentially on the basis of spatial location. Most differential responses of 99 neurons during the object phase were conditional upon place-object relation or reward/nonreward contingency. We will discuss these two correlates and some of their implications for septal functions separately. 


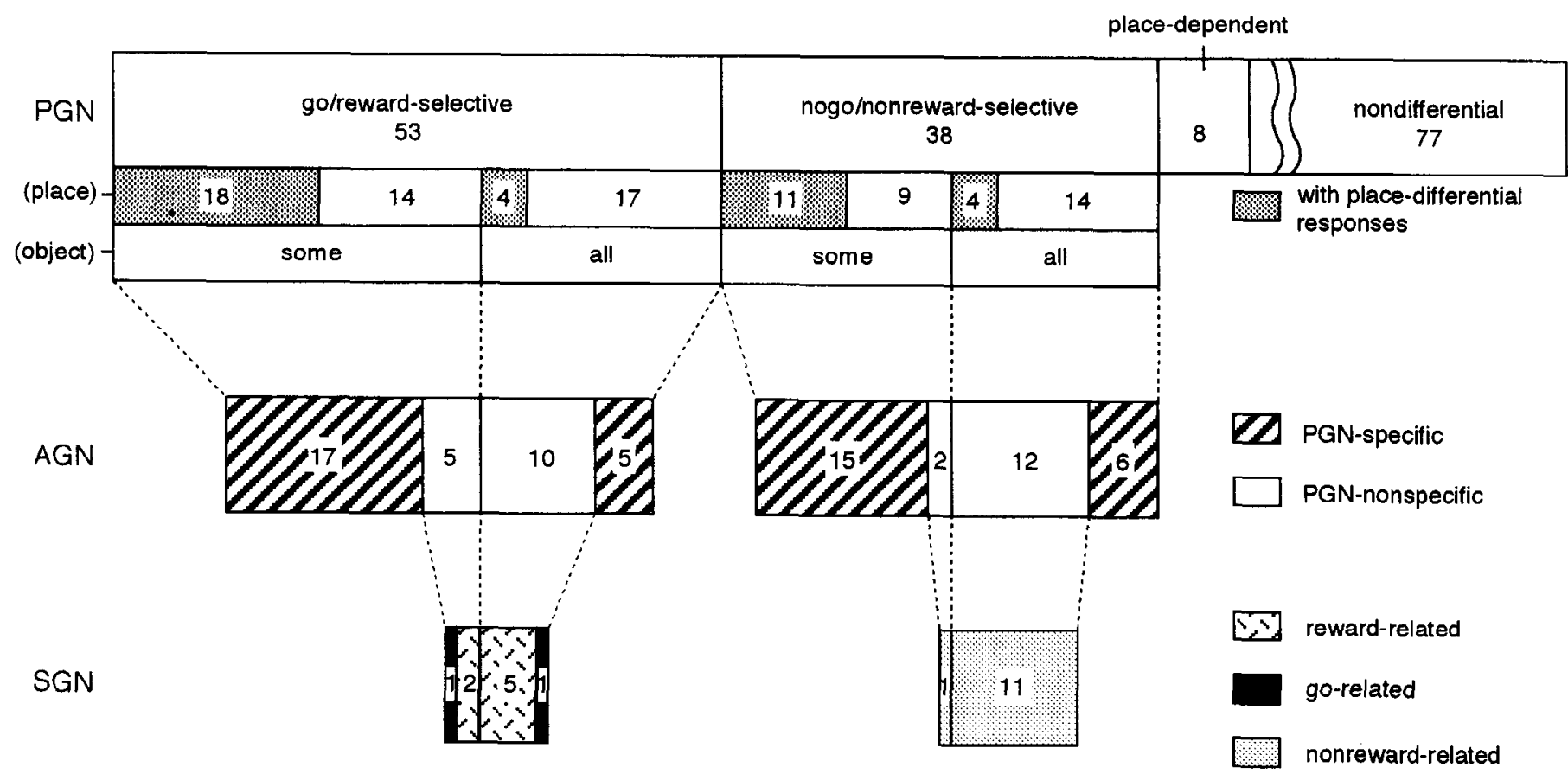

Figure 12. Distribution of neurons with object-phase response based on the responsiveness in each of the PGN, AGN and SGN tasks. all, Activity induced by all four objects; some, activity induced by one or more but not by all objects.

\section{Place-differential responses}

It has been demonstrated that hippocampal place units in rats increase their firing rates in specific spatial locations during either free movement (O'Keefe, 1976; O'Keefe and Conway, 1978; Muller et al., 1987; Wilson and McNaughton, 1993), or a spatial memory task (O'Keefe and Speakman, 1987; Speakman and O'Keefe, 1989). Activity of monkey hippocampal neurons was also reported to be place related (Ono et al., 1991, 1993; Nishijo et al., 1993). The present results first showed that a population of septal neurons (13.5\% of total) fired differentially during presentation of distal environmental cues in a spatial memory task.

In the PGN task used here, animals wcrc placed in any onc of four places where the mode of presentation of the objects and availability of juice reward were similar. The task was so designed that the animals would be expected to have similar expectation for each place, and could not know, during the place phase, which object (rewarding or nonrewarding) might be presented in that trial. Therefore, it is unlikely that the place-related response described in this study can be ascribed to changes in attention, motivation or behavior in a particular place.

It has been reported that darkening the room did not affect the activity of most place-related neurons in rat hippocampi (O'Keefe, 1976). Consistently, animals can navigate in a familiar environment in darkness by relying on inertial directional information provided by the vestibular system (McNaughton et al., 1991). However, in the present study, randomized movement of the monkey cab was intended to make it complicated and difficult for the monkey to determine its location from inertial directional information. Animals can also identify locations by auditory, olfactory, tactile, or proprioceptive cues that are not perceived by the experimenter, so visual cues need not be the sole cause of place-related neural activity. In the present experiments the monkeys probably did not utilize nonvisual information, including vestibular, since omission of visual informa- tion in a reversed object place version of the PGN task, while other nonvisual cues were provided, decreased their performance to the chance level. Furthermore, in the control phase of each trial, during which timc the cab was located at the same place as in the place phase but the outside view was not available, place-differential septal neurons did not change their activity. Thus, the response difference in the place phase depended on the visible information outside of the cab.

Place-differential responses might be ascribed to response to specific cues in the environment, but this is unlikely. In the present experiments, similar sets of distant cues were visible from the four places in the $2.5 \times 2.5 \mathrm{~m}$ field in a room. Furthermore, in two of four neurons tested, manipulation of a table did not affect place-related activity. Similar persistence of spatial related responses after removal of visual cues has also been reported in rat hippocampal neurons (O'Keefe and Conway, 1978). In the other two neurons table movement decreased the place-differential responses transiently, but the responses resumed regardless of the positions of a table as the monkey learned the new environment. Similar ignoring of unstable landmarks in spatial representation has been reported from behavioral study of rats (Biegler and Morris, 1993). Fornix lesion study in the monkey suggested that the septohippocampal system is particularly involved in representation of scenes that differ only in the spatial arrangement of their contents (Gaffan and Harrison, 1989b). From these facts, the place-differential response observed in the present study was concluded to depend on perception of the complex visual scenes rather than on a single salient cue outside of the cab.

During the PGN task, the spatial information about each location of the monkey served as a conditional cue to discriminate the object presented. More place-differential neurons than placenondifferential neurons were contingency-differential responsive which was specitic to the conditional task (PGN specific). Therefore, their differential responses during the place phase might 

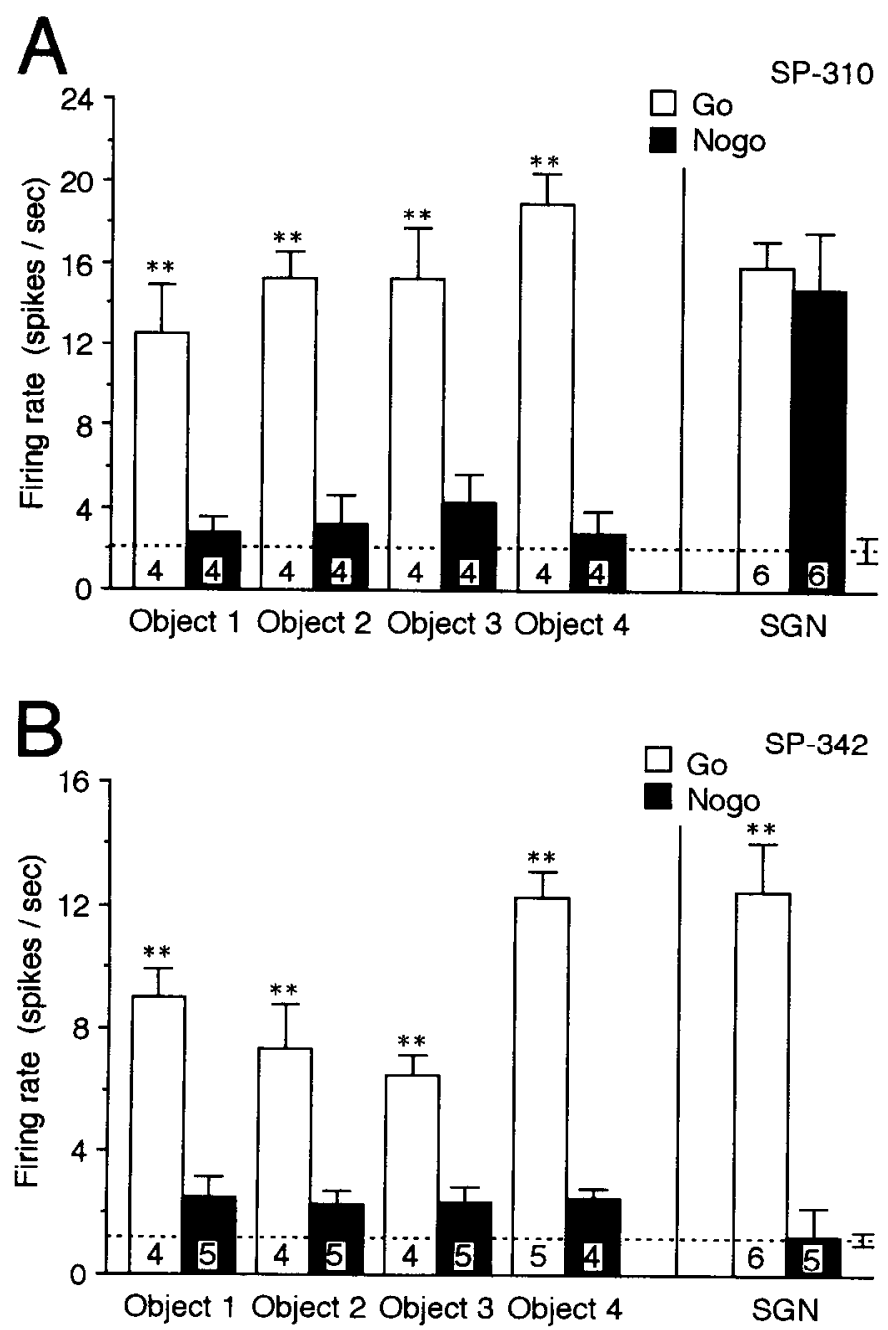

Figure 13. Activity of a both-phase neuron $(A)$ with place-nondifferential response (not shown) and reward-related response, and an objectphase neuron $(B)$ with go-related response. Histograms of mean firing rate ( \pm SEM) to sight of each object for go and no-go trials regardless of animal's location in the PGN (Objects $1-4$ ) and symmetrical go/nogo (SGN) tasks. $\Lambda$, Differential responses to objects indicating reward contingency in the PGN and SGN tasks. **, Significantly different responses to objects indicating reward and nonreward contingencies (Mann-Whitney $U$ test, $p<0.01$ ). $B$, Differential responses to objects indicating go contingency in the PGN and SGN tasks. **, Significantly different responses to objects indicating go and no-go contingencies (Mann-Whitney $U$ test, $p<0.01$ ). Other descriptions as for Figure 4.

reflect recognition of conditional relations between place and object.

On the other hand, some other neurons exhibited place dependence in the object phase as well as in the place phase, and their responses to given objects were not related to the conditional response/reinforcement contingency. The probe trials of reversed object place version of the PGN task revealed that such responses disappeared if the preceding place cue was eliminated, even though a stimulus presented during the object phase was identical. This suggests that the place-dependent response in the object phase reflected the association of a given object with visual information about a particular place(s). Similar response increase has been reported in the monkey hippocampus (Ono et al., 1993) when the monkey saw an object in a specific location.

\section{Contingency-differential responses}

Differential responses were emitted by $21.2 \%$ of the septal neurons during the object phase in the PGN task with respect to the response/reinforcement contingency indicated by the conditional place-object relations. It should be emphasized that these contingency-differential responses were not ascribed to the physical properties of the objects, since the go/reward-selective neurons responded more strongly to given objects in the go trials than in the no-go trials and the no-go/nonreward-selective neurons responded conversely although identical objects were presented.

Perhaps the most significant finding reported here is that many of the contingency-differential neurons that could also he tested in the AGN task did not respond differentially in this unconditional go/no-go task (PGN-specific). Thus, a PGN-specific neuron did not merely reflect a simple response or reinforcement contingency itself, but responded to conditional place-object relations. As far as we know, this type of neural activity has not been previously reported, in any brain structure.

The PGN-nonspecific neurons responded similarly in both the conditional (PGN) and the unconditional (AGN) go/no-go tasks. Since, in these asymmetrical (PGN and AGN) tasks, reward was always coupled with go response and nonreward with no-go response, it is difficult to determine whether these contingencydifferential responses were correlated to reward availability, or to the animal's response. To obtain this kind of information, an SGN task, in which both go and no-go responses were equally associated with juice reward, were introduced. The neural response patterns in the PGN and SGN tasks indicated that most of the neurons tested $(19 / 21,90.5 \%)$ increased activity, regardless of the behavioral responses, only when an object was either rewarding or nonrewarding. Furthermore, these reward/nonreward-contingency-related responses were modulated reversibly by direct manipulation of reward availability (extinction and relearning) in five of seven neurons tested in the present study. This confirms results of previous recording studies (Wilson and Rolls, 1990ab; Fukuda et al., 1993) in which neural response in the monkey basal forebrain including the diagonal band of Broca reflected reinforcement availability during visual discrimination.

\section{Functional role in solving conditional discrimination}

Septal neural responses related to conditional discrimination have not been previously reported. So far, two different types of conditional association learning such as PGN and SGN tasks have often been treated together as a conditional task, but they seem to depend on different brain systems, as discussed below. One type of conditional association learning requires differentiation between variable meanings (reward or nonreward) of stimuli based on cues (conditional stimulus-reinforcement association), while in the other type, selection of proper instrumental response is determined by a corresponding exteroceptive stimulus (conditional stimulus-response association). The PGN task is representative of the former type, and the SGN task is included in the latter type (Petrides, 1986). Combination of these two tasks should allow determination of neural correlation to either type of conditional association.

In rodents, the behavior after fornix and hippocampal lesions suggests that the hippocampal system is essential for learning conditional stimulus-reinforcement association regardless of spatial factors (Hirsh, 1980; Ross et al., 1984; Sutherland and Rudy, 1989; Good and IIoney, 1991; but see Markowska et al., 1989). However, studies of human patients (Petrides, 1990) and non- 
A

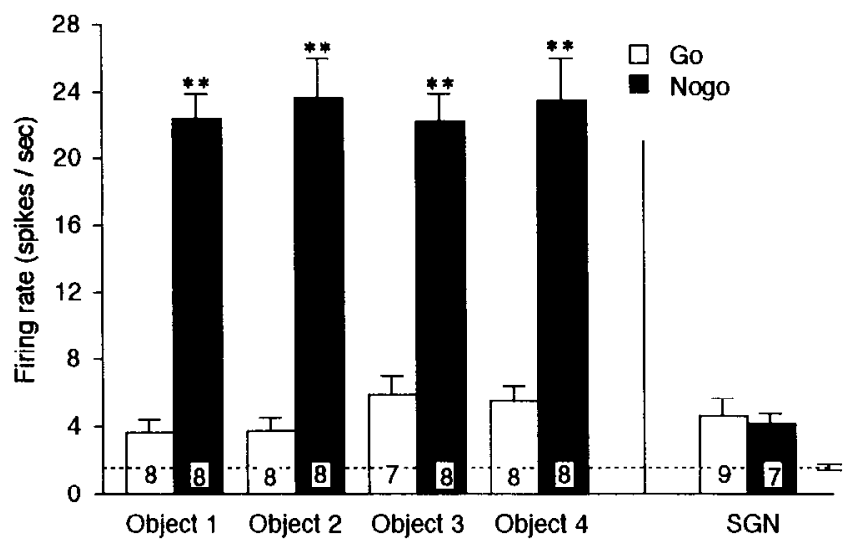

B

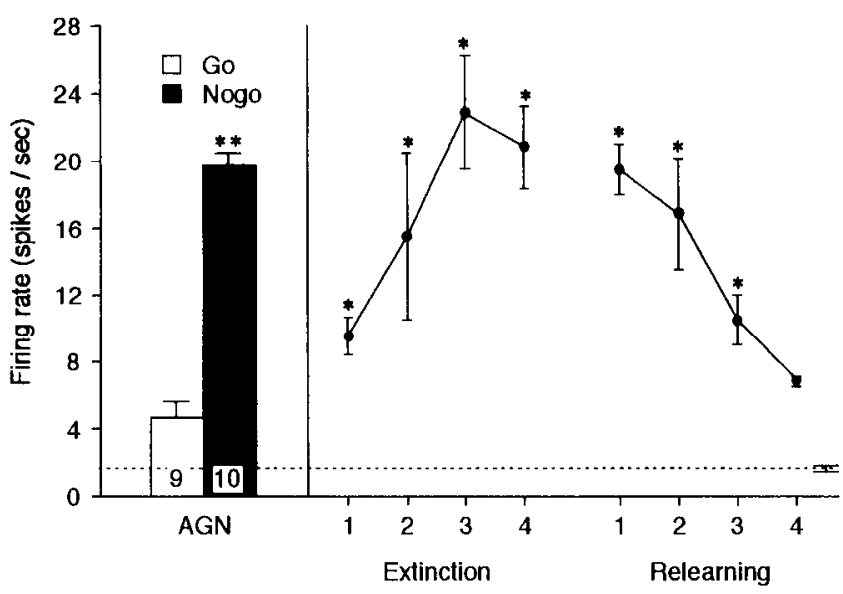

C. Yellow object (nonreward)

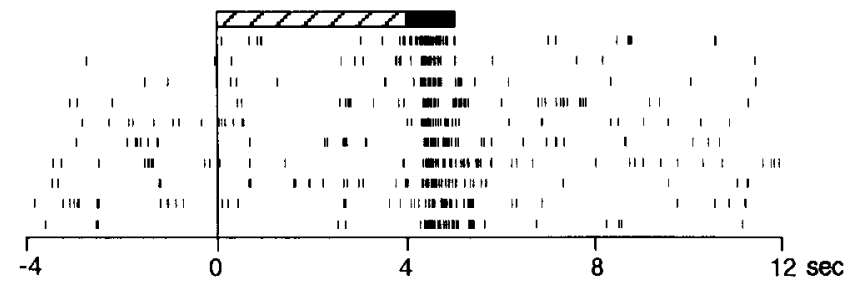

D. White object (reward)

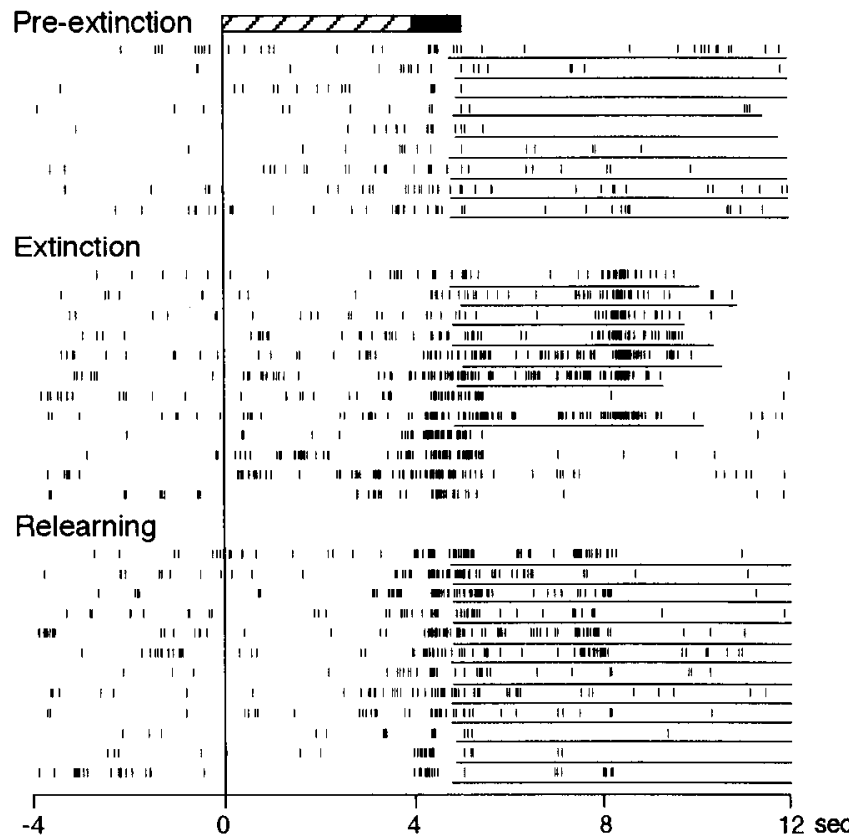

Figure 14. Activity of an object-phase neuron with nonreward-related response $(A-D)$ and influence of extinction and subsequent relearning $(B$ and $D$ ). $A$, Differential responses to objects indicating nonreward contingency in the PGN and SGN tasks. Histograms of mean firing rate $( \pm$ SEM) to sight of each object are shown for go and no-go trials regardless of animal's location in the PGN (Objects $1-4)$ and symmetrical go/no-go (SGN) tasks. **, Significantly different responses to objects indicating reward and nonreward contingencies (Mann-Whitney $U$ test, $p<0.01$ ). There were no differences between responses to objects indicating go and no-go contingencies in the SGN tasks. $B$, Response change to the white object is shown in pre-extinction, extinction and relearning trials. Left histograms indicate responses to objects indicating reward and nonreward contingencies in the AGN tasks in pre-extinction trials. **. Significantly different responses to objects indicating reward and nonreward contingencies (MannWhitney $U$ test, $p<0.01$ ). Right, Broken lines indicate mean and SEM of three trials during extinction and relearning trials. *, Significant difference from the pre-extinction trials (Mann-Whitney $U$ test, $p<0.05$ ). $C$, Raster displays showing responses to the nonrewarding yellow object in the AGN task. Only no-go/nonreward trials were accumulated. $D$, Raster displays showing responses to the rewarding white object during pre-extinction, extinction and relearning trials. Lines under each raster indicate lever presses. Other descriptions as for Figures 4 and 9.

human primates (Petrides, 1985a) demonstrated that lesions of the prefrontal cortex, especially the periarcuate cortex of monkeys, but not of the hippocampus, impaired ability to choose the correct object in a task in which the correct choice was conditional upon a nonspatial visual stimulus. On the other hand, spatial-visual conditional discrimination was related to the septohippocampal system (Gaffan and Harrison, 1989ab) and to the principal sulcus of the prefrontal cortex (Soper, 1979; Gaffan and Harrison, 1989a) in monkeys. However, fornix lesioned monkeys could solve the spatial-visual conditional discrimination when the scenes differed in their contents as reported by Gaffan and his colleagues (Gaffan and Harrison, 1989ab; Murray et al., 1989). This is probably due to the animal being able to recognize differences among the scenes based on differences

Figure 15. Distributions of all neurons recorded. Open symbols, excitation; solid symbols, inhibition; circles, place-phase neurons; squares, objectphase neurons; triangles, both-phase neurons; dots, visually nonresponsive neurons. $A C$, Anterior commissure; $A M$, amygdala; $C D$, caudate; $d b B$, nuclei of the diagonal band of Broca; $L S$, lateral septal nuclei; $L V$, lateral ventricle; $M S$, medial septal nuclei; $P T$, putamen. Numbers above each section indicate distance $(\mathrm{mm})$ anterior from the interaural line.

Figure 16. Distributions of contingency-differential, place-dependent, and nondifferential neurons. Open circles, go/reward-selective neurons; solid circles, no-go/nonreward-selective neurons; inverted open triangles, place-dependent neurons; crosses, nondifferential neurons. Other descriptions as for Figure 15. 

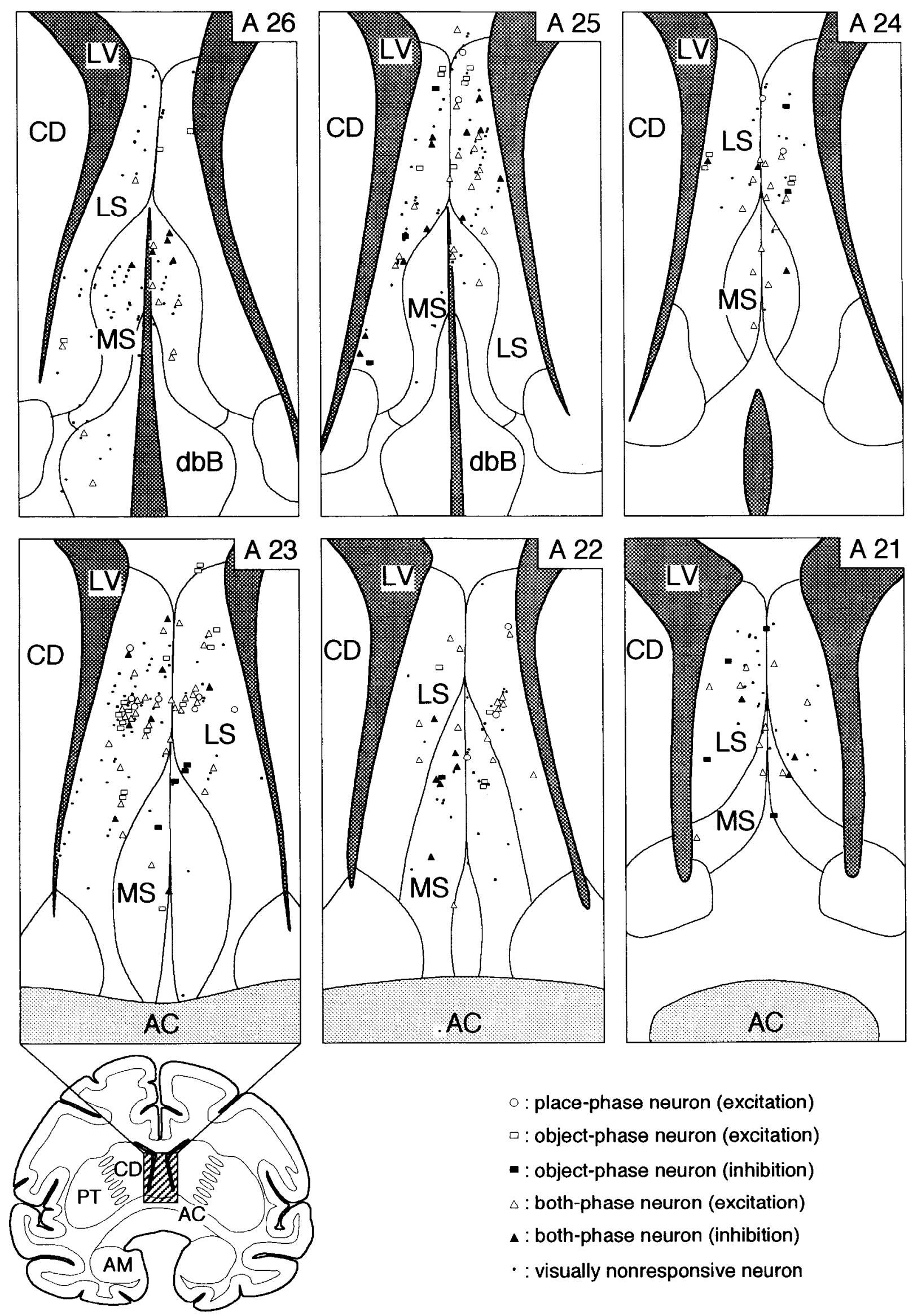

0 : place-phase neuron (excitation)

$\square$ : object-phase neuron (excitation)

- : object-phase neuron (inhibition)

$\triangle$ : both-phase neuron (excitation)

$\Delta$ : both-phase neuron (inhibition)

$\because$ : visually nonresponsive neuron 

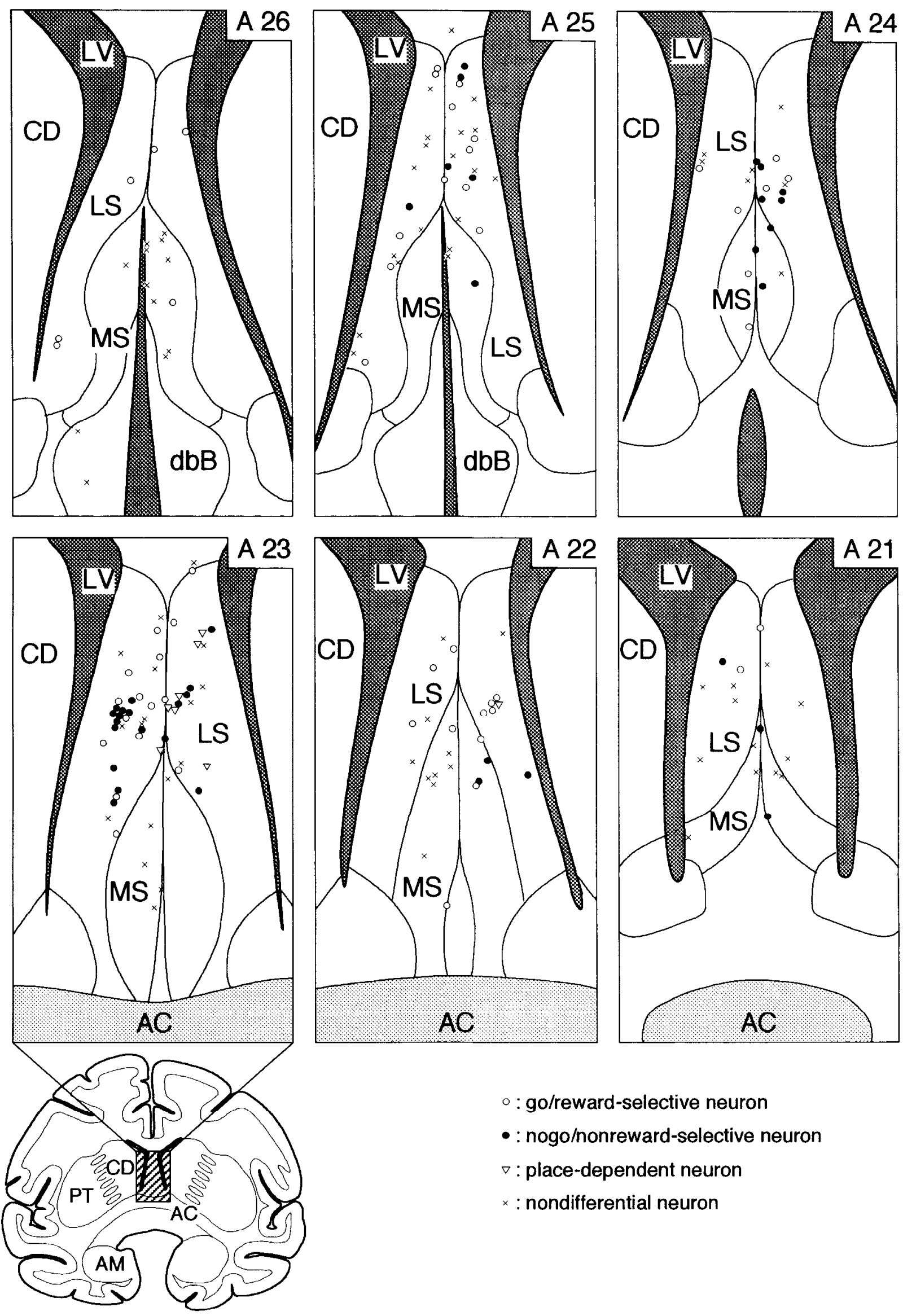

$\circ$ : go/reward-selective neuron

- : nogo/nonreward-selective neuron

$\nabla:$ place-dependent neuron

$x$ : nondifferential neuron 

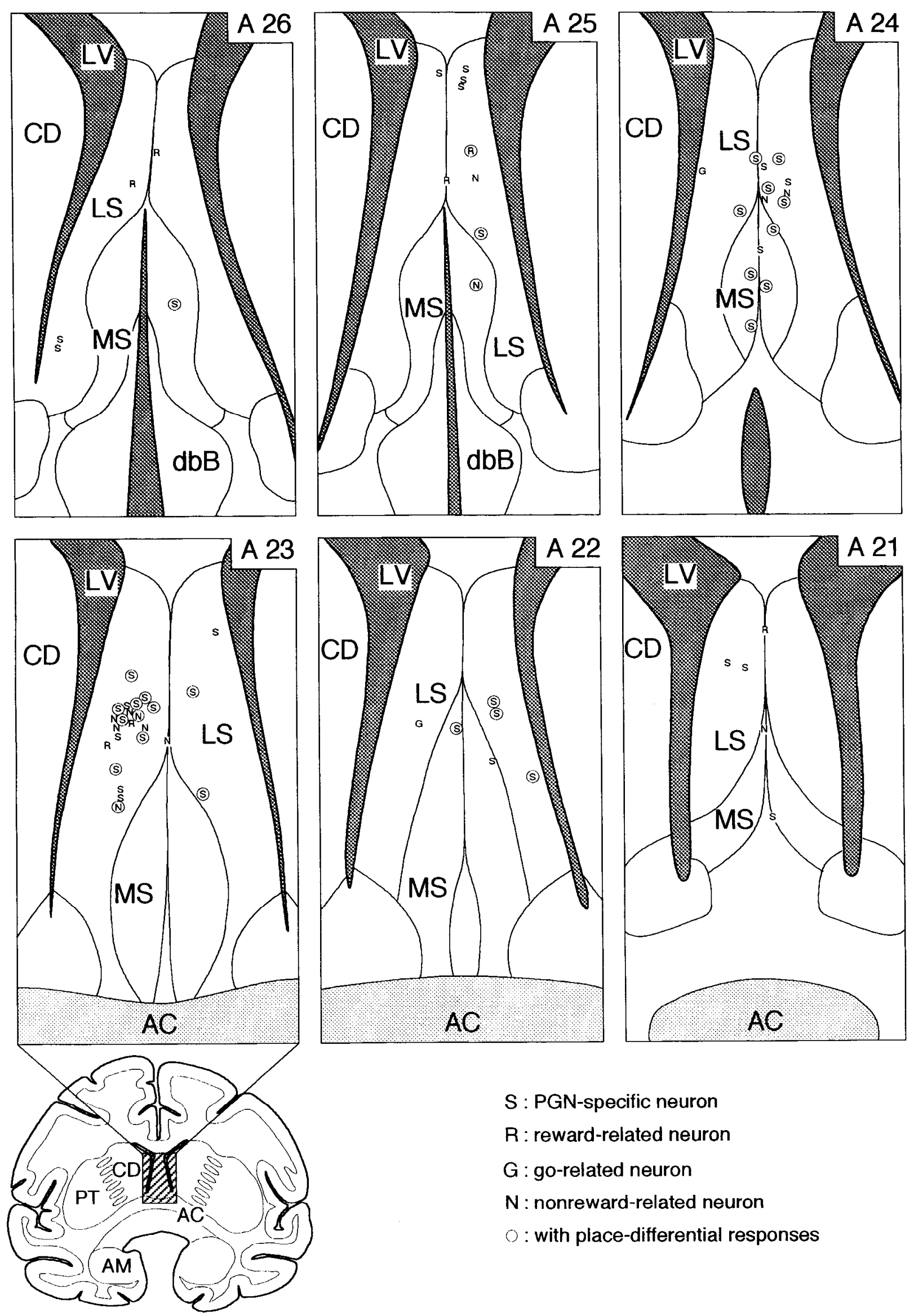

$S$ : PGN-specific neuron

$\mathrm{R}$ : reward-related neuron

$\mathrm{G}$ : go-related neuron

$\mathrm{N}$ : nonreward-related neuron

$O$ : with place-differential responses 
of particular salient objects in different scenes rather than discriminating difference in spatial arrangement of the contents. The present results provide neurophysiological evidence that a population of monkey septal neurons could encode conditional place-object association. Anatomically, it has been reported that both the hippocampus and the septal nuclei are connected to the principal sulcus in monkeys (Tanaka and Goldman, 1976; Goldman-Rakic et al., 1984). Taken together, in primates, the septohippocampal system and the principal sulcus might function cooperatively when the stimulus-reward association depends on the spatial context, but not on nonspatial stimuli.

On the other hand, the periarcuate, but not periprincipal, region of the prefrontal cortex has been identified as a critical conditional stimulus-response association region in the monkey (Stamm, 1973; Milner et al., 1978; Petrides, 1986; also see Rupniak and Gaffan, 1987). Observations of human patients with selective brain excisions indicate that both the hippocampus and the frontal cortex are indispensable for learning appropriate responses, such as pointing towards different positions or producing various hand postures that are conditional upon the particular stimuli (Petrides, 1985b). However, the necessity of a septal connection with the hippocampus in this stimulus-response association is rather questionable since monkeys with fornix lesions could solve a visuomotor conditional learning of hold and tap responses (Gaffan and Harrison, 1988) and lesions in the medial septal nuclei failed to impair rat performance in the symmetrical go/no-go task (Numan and Klis, 1992; also see Thomas and Gash, 1986). In the present results, few septal neurons were related to response contingency in the SGN task. This evidence strongly suggests less participation of the septal nuclei in learning conditional stimulus-response association, and is consistent with such behavioral observations.

\section{Relation to hippocampal formation}

Septal nuclei and the hippocampal formation have been suggested to act as one functional unit by behavioral (Gray and McNaughton, 1983; Gaffan and Harrison, 1989b) and anatomical (Swanson et al., 1987) results. There is some earlier evidence to suggest that the present place-differential and contingencydifferential responses in the septal nuclei are related to the hippocampal neural activity. First, rat hippocampal neurons were often reported to respond to various combinations of sensory stimulus and place (Wible et al., 1986; Wiener and Eichenbaum, 1989; Sharp et al., 1990). In monkeys, some hippocampal neurons responded only when a stimulus was presented in a particular position (Watanabe and Niki, 1985; Rolls et al., 1989), or only when an animal saw an object from a particular direction (Tamura et al., 1992), or when the animal was in a particular location (Ono et al., 1991, 1993; Nishijo et al., 1993). These previous results indicated that a population of hippocampal neurons could differentially encode information about a given object with reference to the spatial location of the object or the animal itself, with or without reference to some biological meaning of the object. Also, one major efferent pathway of the hippocampus enters the lateral septal nuclei (Raisman, 1966; Swanson et al., 1987). Long-term potentiation, regarded as a cellular mechanism of learning (Lynch and Baudry, 1984; McNaughton and Morris,
1987), was reported in these hippocampal-septal synapses (Stevens and Cotman, 1991). Indeed, some septal neurons in rats (Thomas et al., 1991) changed their activity during learning, and some of the place-differential neurons affected by table movement recovered their activities during relearning in the present study. Taken together, septal neurons could receive spatially organized information such as place-object relation from the hippocampus, and this information might be further processed during learning in the septal nuclei.

In the present study, place-differential neurons with contingency-differential responses were often located in the lateral septal nuclei. Most of these place-differential neurons showed contingency-differential responses to some, but not all, of the four objects used in the PGN task. This suggests that formation of conditional place-object relations for all four objects may be based on the activity of a population of neurons with contingency-differential responses to different object(s). This information may be transferred to neurons with contingency-differential responses that were induced by all of the four objects. Thus, the spatially organized information is likely to be integrated with a reward/nonreward contingency mainly in the lateral septal nuclei. Two-thirds of the septal neurons with contingency-differential responses for all of the four objects responded regardless of the PGN and AGN tasks. This suggests that these neurons were concerned with reward/nonreward discrimination.

The medial septal nuclei may receive information from the lateral septal nuclei directly or via other structures (Leranth et al., 1992; Witter et al., 1992). Consistently, some nonrewardrelated neurons were located in the medial septal nuclei in the present study. In previous studies, many reward-contingency related ncurons wcre also located in both the medial septal nuclei and the diagonal band of Broca (Wilson and Rolls, 1990ab; Fukuda et al., 1993), from which afferent fibers to the hippocampal formation originate. Therefore, information regarding reward/ nonreward contingency might be sent back to the hippocampal formation. Accordingly, reinforcement-contingency affected some hippocampal neural activity (Deadwyler et al., 1979; Eichenbaum et al., 1987; Olton, 1989), and this modulation of hippocampal activity may have depended on such septal inputs, as proposed by Deadwyler et al. (1979).

In summary, the present results provide neurophysiological evidence of septal participation in spatial coding and integration of conditional relations. In this broader perspective, the conditional place-object discrimination used in this study may be a special case among numerous functional contributions of the septal nuclei (for review, see Gray and McNaughton, 1983).

\section{References}

Ammassari-Teule M, Amoroso D, Forloni GL, Rossi-Arnaud C, Consolo S (1993) Mechanical deafferentation of basal forebrain-cortical pathways and neurotoxic lesions of the nucleus basalis magnocellularis: comparative effect on spatial learning and cortical acetylcholine release in vivo. Behav Brain Res 54:145-152.

Beckstead RM (1979) An autoradiographic examination of corticocortical and subcortical projections of the mediodorsal-projection (prefrontal) cortex in the rat. J Comp Neurol 184:43-62.

Biegler R, Morris GM (1993) Landmark stability is a prerequisite for spatial but not discrimination learning. Nature 361:631-633.

Brito GNO, Brito LSO (1990) Septohippocampal system and the pre- 
limbic sector of frontal cortex: a neuropsychological battery analysis in the rat. Behav Brain Res 36:127-146.

Brito GNO, Thomas GJ, Davis BJ, Gingold SI (1982) Prelimbic cortex, mediodorsal thalamus, septum, and delayed alternation in rats. Exp Brain Res 46:52-58.

Burman DD, Segraves MA (1994) Primate frontal eye field activity during natural scanning eye movements. J Neurophysiol 71:12661271.

Butters N, Rosvold HE (1968) Effect of septal lesions on resistance to extinction and delayed alternation in monkeys. J Comp Physiol Psychol 66:389-395.

Deadwyler SA, West M, Lynch G (1979) Activity of dentate granule cells during learning: differentiation of perforant path input. Brain Res 169:29-43.

Fichenhaum H, Clegg RA, Feeley A (1983) Reexamination of functional subdivisions of the rodent prefrontal cortex. Exp Neurol 79: $434-451$.

Eichenbaum H, Kuperstein M, Fagan $\Lambda$, Nagode J (1987) Cue-sampling and goal approach correlates of hippocampal unit activity in rats performing an odor-discrimination task. J Neurosci 7:716-732.

Fukuda M, Masuda R, Ono T, Tabuchi E (1993) Responses of monkey basal forebrain neurons during visual discrimination task. Prog Brain Res 95:359-369.

Gaffan D, Harrison S (1988) Inferotemporal-frontal disconnection and fornix transection in visuomotor conditional learning by monkeys. Behav Brain Res 31:149-163.

Gaffan D, Harrison S (1989a) A comparison of the effects of fornix transection and sulcus principalis ablation upon spatial learning by monkeys. Behav Brain Res 31:207-220.

Gaffan D, Harrison S (1989b) Place memory and scene memory: effects of fornix transection in the monkey. Exp Brain Res 74:202212.

Goldman-Rakic PS, Selemon LD, Schwartz ML (1984) Dual pathways connecting the dorsolateral prefrontal cortex with the hippocampal formation and parahippocampal cortex in the rhesus monkey. Neuroscience 12:719-743.

Good M, Honey RC (1991) Conditioning and contextual retrieval in hippocampal rats. Behav Neurosci 105:499-509.

Gray JA, McNaughton N (1983) Comparison between the behavioural effects of septal and hippocampal lesions: a review. Neurosci Behav Rev 7:119-188.

Hirsh R (1980) The hippocampus, conditional operations, and cognition. Physiol Psychol 8:175-182.

Jaskiw GE, Tizabi Y, Lipska BK, Kolachana BS, Wyatt RJ, Gilad GM (1991) Evidence for a frontocortical-septal glutamatergic pathway and compensatory changes in septal glutamate uptake after cortical and fornix lesions in the rat. Brain Res 550:7-10.

Kolb B (1984) Functions of the frontal cortex of the rat: a comparative review. Brain Res Rev 8:65-98.

Kusama T, Mabuchi M (1970) Stereotaxic atlas of the brain of Macaca fuscata. Tokyo: Tokyo UP.

Leranth C, Deller T, Buzsáki G (1992) Intraseptal connections redefined: lack of a lateral septum to medial septum path. Brain Res 583:111.

Lynch G, Baudry M (1984) The biochemistry of memory: a new and specific hypothesis. Science 224:1057-1063.

Markowska AL, Olton DS, Murray EA, Gaffan D (1989) A comparative analysis of the role of fornix and cingulate cortex in memory: rats. Exp Brain Res 74:187-201.

McNaughton BL, Morris RGM (1987) Hippocampal synaptic enhancement and information storage within a distributed memory system. Trends Neurosci 10:408-415.

McNaughton BL, Chen LL, Markus EJ (1991) "Dead reckoning," landmark learning, and the sense of direction: a neurophysiological and computational hypothesis. J Cog Neurosci 3:190-202.

Milner AD, Forman NP, Goodale MA (1978) Go-left go-right discrimination performance and distractibility following lesions of prefrontal cortex or superior colliculus in stumptail macaques. Neuropsychology $16: 381-390$.

Mishkin M (1957) Effects of small frontal lesions on delayed alternation in monkeys. J Neurophysiol 20:615-622.

Muller RU, Kubie JL, Ranck JB Jr (1987) Spatial firing patterns of hippocampal complex-spike cells in a fixed environment. J Neurosci 7:1935-1950.

Murray EA, Davidson M, Gaffan D, Olton DS, Suomi S (1989) Effects of fornix transection and cingulate cortical ablation on spatial memory in rhesus monkeys. Exp Brain Res 74:173-186.

Nishijo H, Ono T, Tamura R, Nakamura K (1993) Amygdalar and hippocampal neuron responses related to recognition and memory in monkey. Prog Brain Res 95:339-357

Numan R, Klis D (1992) Effects of medial septal lesions on an operant delayed go/no-go discrimination in rats. Brain Res Bull 29:643-650.

O'Keefe J (1976) Place units in the hippocampus of the freely moving rat. 51:78-109.

O'Keefe J, Conway DH (1978) Hippocampal place units in the freelymoving rat: why they fire where they fire. Exp Brain Res 31:573590

O'Keefe J, Nadel L (1978) The hippocampus as cognitive map. Oxford: Clarendon.

O'Keefe J, Speakman A (1987) Single unit activity in the rat hippncampus during a spatial memory task. Exp Brain Res 68:1-27.

Olton DS (1989) Mnemonic functions of the hippocampus: single unit analyses in rats. In: The hippocampus - new vistas (Chan-Palay V, Köhler C, eds), pp 411-424. New York: Liss.

Ono T, Nakamura K, Fukuda M, Tamura R (1991) Place recognition responses of neurons in monkey hippocampus. Neurosci Lett 121: 194-198.

Ono T, Nakamura K, Nishijo H, Eifuku S (1993) Monkey hippocampal neurons related to spatial and nonspatial functions. J Neurophysiol 70:1516-1529

Petrides M (1985a) Deficits in non-spatial conditional associative learning after periarcuate lesions in the monkey. Behav Brain Res 16:95-101.

Petrides M (1985b) Deficits on conditional associative-learning tasks after frontal- and temporal-lobe lesions in man. Neuropsychology 23: 601-614.

Petrides M (1986) The effect of periarcuate lesions in the monkey on the performance of symmetrically and asymmetrically reinforced visual and auditory Go, No-Go tasks. J Neurosci 6:2054-2063.

Petrides M (1990) Nonspatial conditional learning impaired in patients with unilateral frontal but not unilateral temporal lobe excisions. Neuropsychology 28:137-149.

Poucet B, Herrmann T (1990) Septum and medial frontal cortex contribution to spatial problem-solving. Behav Brain Res 37:269-280.

Raisman G (1966) The connexions of the septum. Brain 89:317-348.

Rolls ET, Miyashita Y, Cahusac PMB, Kesner RP, Niki H, Feigenbaum JD, Bach L (1989) Hippocampal neurons in the monkey with activity related to the place in which a stimulus is shown. J Neurosci 9:1835-1845.

Rosenkilde CE (1983) Functions of the prefrontal cortex. Acta Physiol Scand [Suppl] 514:1-58.

Ross R T, Orr WB, Holland PC, Berger TW (1984) Hippocampectomy disrupts acquisition and retention of learned conditional responding. Behav Neurosci 98:211-225.

Rupniak NMJ, Gaffan D (1987) Monkey hippocampus and learning about spatially directed movements. J Neurosci 7:2331-2337.

Sharp PE, Kubie JL, Muller RU (1990) Firing properties of hippocampal neurons in a visually symmetrical environment: contributions of multiple sensory cues and mnemonic processes. J Neurosci 10:3093. 3105.

Shaw C, Aggleton JP (1993) The effects of fornix and medial prefrontal lesions on delayed non-matching-to-sample by rats. Behav Brain Res 54:91-102.

Siegel A, Ohgami S, Edinger H (1975) Projections of the hippocampus to the septal area in the squirrel monkey. Brain Res 99:247-260.

Soper HV (1979) Principal sulcus and posterior parieto-occipital cortex lesions in the monkey. Cortex 15:83-96.

Speakman A, O'Keefe J (1989) Hippocampal place cells and hippocampal theories. In: The hippocampus - new vistas (Chan-Palay V, Köhler C, eds), pp 425-441. New York: Liss.

Stamm JS (1973) Functional dissociation between the inferior and arcuate segments of dorsolateral prefrontal cortex in the monkey. Neuropsychology 11:181-190.

Stevens DR, Cotman CW (1991) Long-term potentiation of excitatory and slow inhibitory synaptic potentials in the hippocampal-septal projection of the rat. Brain Res 558:120-122.

Sutherland RJ, Rudy JW (1989) Configural association theory: the role of the hippocampal formation in learning, memory, and amnesia. Psychobiology 17:129-144.

Sutherland RJ, Kolb B, Whishaw IQ (1982) Spatial mapping: definitive 
disruption by hippocampal or medial frontal cortical damage in the rat. Neurosci Lett 31:271-276.

Swanson LW, Köhler C, Björklund A (1987) The limbic region. I. The septohippocampal system In: Handbook of chemical neuroanatomy, Vol 5 (Björklund A, Hökfelt T, Swanson LW, eds), pp 125-277. New York: Elsevier.

Tamura R, Ono T, Fukuda M, Nakamura K (1992) Spatial responsiveness of monkey hippocampal neurons to various visual and auditory stimuli. Hippocampus 2:307-322.

Tanaka D, Goldman PS (1976) Silver degeneration and autoradiographic evidence for a projection from the principal sulcus to the rhesus monkey. Brain Res 103:535 540.

Thomas E, Yadin E, Strickland CE (1991) Septal unit activity during classical conditioning: a regional comparison. Brain Res 547:303308.

Thomas GJ, Gash DM (1986) Differential effects of posterior septal lesions on dispositional and representational memory. Behav Neurosci 100:712-719.

Thomas GJ, Spafford PS (1984) Deficits for representational memory induced by septal and cortical lesions (singly and combined) in rats Behav Neurosci 98:394-404.

Watanabe T, Niki H (1985) Hippocampal unit activity and delayed response in the monkey. Brain Res 325:241-254.

Wible CG, Findling RL, Shapiro M, Lang EJ, Crane S, Olton DS (1986) Mnemonic correlates of unit activity in the hippocampus. Brain Res 399:97-110.

Wiener SI, Eichenbaum H (1989) Spatial and behavioral correlates of hippocampal neuronal activity. J Neurosci 9:2737-2763.

Wilson FAW, Rolls ET (1990a) Learning and memory is reflected in the responses of reinforcement-related neurons in the primate basal forebrain. J Neurosci 10:1254-1267.

Wilson FAW, Rolls ET (1990b) Neuronal responses related to reinforcement in the primate basal forebrain. Brain Res 509:213-231.

Wilson MA, McNaughton BL (1993) Dynamics of the hippocampal ensemble code for space. Science 261:1055-1058.

Witter MP, Daelmans HEM, Jorritsma-Byham B, Staiger JF, Wouterlood FG (1992) Restricted origin and distribution of projections from the lateral to the medial septal complex in rat and guinea pig. Neurosci Lett 148:164-168. 